\title{
LA DUCTILIDAD DEL DERECHO PARLAMENTARIO EN TIEMPOS DE CRISIS: ACTIVIDAD Y FUNCIONAMIENTO DE LOS PARLAMENTOS DURANTE EL ESTADO DE ALARMA POR COVID-19
}

\author{
PIEDAD GARCÍA-ESCUDERO MÁRQUEZ \\ Catedrática de Derecho Constitucional \\ Universidad Complutense de Madrid
}

TRC, núm. 46, 2020, pp. 271-308

ISSN 1139-5583

\begin{abstract}
SUMARIO
I. Introducción. La actividad parlamentaria en situación de crisis sanitaria. II. Parlamentos disueltos: País Vasco y Galicia. III. Mantenimiento de la actividad por medios presenciales o telemáticos. IV. Activación de la Diputación permanente. V. Congreso de los Diputados...y Senado.
\end{abstract}

\section{INTRODUCCIÓN. LA ACTIVIDAD PARLAMENTARIA EN SITUACIÓN DE CRISIS SANITARIA}

El título de este trabajo se ha tomado de un informe de los servicios jurídicos de un Parlamento autonómico, en el que se esgrime la ductilidad del Derecho parlamentario para admitir la posibilidad de alguna actuación de dudoso encaje en el Reglamento.

La declaración del estado de alarma el 14 de marzo de 2020 como consecuencia de la pandemia COVID-19 y la existencia de parlamentarios contagiados incluso antes de aquella, han provocado graves interferencias en el funcionamiento de los distintos Parlamentos, que condujeron en nuestro país a buscar diversas soluciones en los Parlamentos autonómicos y en las Cámaras que integran las Cortes Generales. Intentaremos en este trabajo sistematizar y comentar las decisiones adoptadas, sin pretender abordar cuestiones más trascendentes, como por ejemplo la suficiencia o no del control ejercido sobre los Gobiernos. 
La peculiaridad de las circunstancias que han dificultado el normal funcionamiento de nuestros Parlamentos no reside en la declaración de un estado de anomalía o emergencia constitucional, que sólo había sido ocurrido una vez desde la aprobación de la Constitución. El problema fundamental ha sido una crisis sanitaria que hacía desaconsejables - y en algún caso impedía — los desplazamientos y la reunión de grupos de personas, más aún procedentes de distintas áreas geográficas. Crisis sanitaria - una pandemia - sin precedentes, con miles de muertos, centenares cada día sólo en España, contándose parlamentarios entre los primeros contagiados — razón añadida para observar una cuarentena y extremar las precauciones-, amén de miembros del Gobierno y otras autoridades.

Ya las Cortes reunidas en Cádiz en 1810 tuvieron que superar los obstáculos que la situación de guerra planteaba. Así, el artículo 109 de la Constitución de 1812 preveía y solventaba las eventuales dificultades de desplazamiento: «Si la guerra o la ocupación de alguna parte del territorio de la Monarquía por el enemigo impidieren que se presenten a tiempo todos o algunos de los Diputados de una o más provincias, serán suplidos los que falten por los anteriores Diputados de las respectivas provincias, sorteando entre sí hasta completar el número que les corresponda».

La crisis provocada por la pandemia ha afectado de lleno a la actividad parlamentaria, en una situación de emergencia para la que el artículo 116 CE reclama la presencia del Congreso de los Diputados, a quien corresponde autorizar la prórroga de la declaración del estado de alarma, de la que se le ha de dar cuenta, «reunido inmediatamente al efecto». Los apartados 5 y 6 de este artículo se preocupan de establecer las cautelas que han de preservar la democracia parlamentaria en una situación de incremento de poder del Ejecutivo y de restricción de derechos ${ }^{1}$.

Muy especialmente el Congreso de los Diputados, al que corresponden competencias específicas en este estado, pero también el Senado y los Parlamentos de las Comunidades Autónomas en el ejercicio de su función de control al Gobierno, se han encontrado en la coyuntura de hacer de la necesidad virtud y enfrentarse a unas circunstancias para las que no contaban no ya con previsión reglamentaria, sino con instrumentos o herramientas tecnológicas — piénsese en la posibilidad de celebrar reuniones telemáticas con garantías- que permitieran continuar con su actividad...de otra forma ${ }^{2}$.

1 Art. 116. «5. No podrá procederse a la disolución del Congreso mientras estén declarados algunos de los estados comprendidos en el presente artículo, quedando automáticamente convocadas las Cámaras si no estuvieren en periodo de sesiones. Su funcionamiento, así como el de los demás poderes del Estado, no podrá interrumpirse durante la vigencia de estos estados. Disuelto el Congreso o expirado su mandato, si se produjere algunas de las situaciones que dan lugar a cualquiera de dichos estados, las competencias del Congreso serán asumidas por su Diputación Permanente. 6. La declaración de los estados de alarma, de excepción y de sitio no modificará el principio de responsabilidad del Gobierno y de sus agentes reconocidos en las Constitución y en las leyes».

2 Para las medidas adoptadas en otros países, entre otros, J. Murphy, Parliaments and Crisis: challenges and innovations, Parliamentary Primer 1, Inter Pares. Parliaments in Partnership, International IDEA, 2020; 
En el origen de las barreras jurídicas a las posibles innovaciones imaginativas — sesiones y/o voto a distancia - se encuentra el carácter presencial de las reuniones de Asambleas, deducible de su propio nombre y que se plasma en distintos artículos de la Constitución en referencia al Congreso y al Senado, en particular las reglas sobre quórum y personalidad e indelegabilidad del voto contenidas en el artículo $79^{3}$. Las recientes sentencias del Tribunal Constitucional 19/2019 y $45 / 2019$, bien es verdad que en un contexto diferente (investidura no presencial del candidato a la Presidencia de la Generalitat), han subrayado la inmediatez y presencialidad de la actividad parlamentaria ${ }^{4}$, aun admitiendo la posibilidad de que los Reglamentos prevean el voto en ausencia cuando concurran circunstancias excepcionales o de fuerza mayor (STC 19/2019 FJ 4).

Las circunstancias de crisis no constituyen el escenario apropiado para las modificaciones reglamentarias, siempre difíciles en determinadas Cámaras, en particular el Congreso y el Senado. Cierto que muchos Parlamentos, por otras causas derivadas en primer término del incremento del número de parlamentarias, han introducido modalidades de voto a distancia o delegado en sesiones plenarias y para determinados asuntos, pero ello no ha sido suficiente en los momentos vividos. Cuestiones como el registro electrónico de iniciativas o la necesidad de guardar distancia entre los asistentes a las sesiones habían de ser cohonestadas con la función de control del Gobierno, especialmente importante en estado de alarma.

A las cuestiones expuestas han dado respuesta los Presidentes, las Mesas, las Juntas de Portavoces, en definitiva los órganos de gobierno de los Parlamentos, ideando soluciones más o menos amparadas por el respectivo Reglamento 5 . En ese más o menos está el problema: por mucha voluntad que haya, no todo vale. La ductilidad del Derecho Parlamentario tiene límites —incluso en el supuesto de

el briefing elaborado por el Servicio de documentación parlamentaria del Parlamento Europeo Parliaments in emergency mode. How Member States' Parliaments are continuing with business during the pandemia (M. DiAz CREGO y R. MANKO); la recopilación realizada por la UIP sobre las respuestas parlamentarias a la pandemia en https:/www.ipu.org/country-compilation-parliamentary-responses-pandemic (cons. 7.09.2020), así como el informe de la Biblioteca del Congreso de los Estados Unidos Continuity of Legislative Activities during Emergency Situations. Véanse también propuestas para el Parlamento británico, «Proposals for a 'virtual' Parliament: how should parliamentary procedure and practices adapt during the Coronavirus pandemic?», en https://hansardsociety.org.uk/publications/proposals-for-a-virtual-parliament (acceso 7.9.2020). La solución adoptada finalmente en los Comunes para la reanudación de trabajos fue mixta, presencial y por videoconferencia.

3 Pueden verse sobre este tema P. García-Escudero Márquez, «Artículo 79», Comentarios a la Constitución Española de 1978, L. M. Cazorla Prieto, dir., tomo I, Thomson Reuters Aranzadi, Cizur Menor, 2018, pp. 2134 y ss., y «Artículo 79», Comentarios a la Constitución española 40 aniversario, Libro homenaje a Luis López Guerra, P. Pérez Tremps y A. Saiz Arnáiz, dirs., tomo I, Tirant lo Blanch, Valencia, 2018, pp. 1219 y ss.

4 La STC 45/2019 FJ 5 y 6 extiende también la inmediatez a las reuniones del Gobierno salvo casos justificados y excepcionales y con las debidas garantías. En este sentido, la crisis sanitaria ha llevado a la modificación de la Ley 50/1997, del Gobierno (nueva disposición adicional tercera), por Real Decreto-ley 7/2020, para permitir las reuniones telemáticas en situaciones excepcionales y cuando la naturaleza de la crisis lo exija.

5 Una amplia panorámica «desde dentro», Cuadernos Manuel Giménez Abad, Monografía 8, junio 2020 
la unanimidad que supuestamente todo lo sana- si queremos mantenernos en el Estado de Derecho.

El estado de alarma fue declarado por el Gobierno por Real Decreto 463/2020, de 14 de marzo (BOE n. 67 del mismo día, minutos antes de las 12 de la noche), entrando en vigor en el momento de su publicación. Ya la semana anterior se había producido la paralización de la actividad en algunas Cámaras: así, la Mesa del Congreso de los Diputados suspendió las sesiones previstas para la semana del 10 de marzo, como también lo hicieron distintos Parlamentos autonómicos. A partir de entonces y durante un mes (hasta el 12 de abril, concluida la primera prórroga del estado declarado), al desatarse la expansión de la enfermedad la actividad parlamentaria se reduce a mínimos, pero incluso esos mínimos precisaron de una adecuación de normas o de acuerdos que estudiaremos a continuación agrupándolos en función de la solución adoptada. Una vez que el 9 de abril el Congreso autoriza una segunda prórroga (con visos de que no sería la última ${ }^{6}$ ) y se levantan algunas restricciones al trabajo presencial en general, la suspensión de su actividad se hace insostenible para los propios Parlamentos y ante la opinión pública, reactivándose aquella, aunque también con formas inhabituales —no siempre acertadas-, todo lo cual intentamos exponer a continuación.

Con carácter previo, ha de destacarse que el tamaño de los Parlamentos autonómicos no es comparable a los del Congreso y el Senado, como tampoco lo es el ámbito territorial de representación, cuya menor amplitud no plantea — salvo en el caso insular por las circunstancias que se dirán - tantos problemas de desplazamiento o de reunión observando las distancias recomendadas entre los asistentes. Ello puede hacer menos justificables determinadas decisiones.

\section{PARLAMENTOS DISUELTOS: PAÍS VASCO Y GALICIA}

En circunstancias particulares se encontraban los Parlamentos de País Vasco y Galicia, con procesos electorales convocados para el día 5 de abril, dejados sin efecto por Decretos del respectivo Presidente de la Comunidad Autónoma (7/2020 y 45/2020) como consecuencia de la declaración del estado de alarma, aun sin previsión legal que lo permitiera.

Disueltos los Parlamentos Vasco y Gallego, sin medio jurídico de «resucitarlos», el único órgano de trabajo vivo era la Diputación Permanente (con su Mesa), de carácter reducido y por tanto más fácil de reunir, si bien con competencias normalmente tasadas.

En Galicia, el Presidente de la Xunta compareció ante la Diputación Permanente el 26 de marzo de 2020 para informar sobre la evolución de la pandemia y

6 Previa la correspondiente autorización del Congreso de los Diputados, el estado de alarma fue prorrogado por periodos de catorce días por RRDD 476, 487, 492, 514, 537 y 555/2020. 
las medidas adoptadas. De conformidad con una Resolución de la Presidencia del Parlamento, el Vicepresidente y Consejero de Presidencia, Administraciones Públicas y Justicia, y la Consejera de Política Social comparecieron el 3 de abril; posteriormente se reuniría la DP con periodicidad semanal a partir del 22 de abril para comparecencias de consejeros y del Presidente de la Xunta. Estas reuniones se celebraron de forma presencial, en el hemiciclo, observando la distancia requerida por la crisis sanitaria (21 miembros titulares), sin la asistencia inmediata de representantes de los medios de comunicación.

Previamente, como en prácticamente todos los parlamentos, el 15 de marzo se habían adoptado medidas de teletrabajo para el personal y la limitación de la presencia en la sede de la institución al mínimo imprescindible, así como el funcionamiento sólo telemático del Registro. Destaquemos desde ahora la importancia que el registro de iniciativas tiene para el funcionamiento del Parlamento, pues la presentación de aquellas constituye el motor que pone en marcha su actividad $^{7}$.

En el Parlamento Vasco, la Mesa de la Diputación Permanente cerró sus edificios el 13 de marzo, tras conocer las medidas adoptadas ese mismo día por el Consejo de Gobierno; posteriormente, la Mesa continuó reuniéndose de forma telemática con regularidad. El Lehendakari se reunió telemáticamente con los portavoces de los grupos parlamentarios «para dar cumplimiento» a una comparecencia solicitada por EH Bildu sobre las medidas tomadas y a tomar, según acuerdo de la Mesa de la Diputación Permanente. El acuerdo justifica esta reunión informativa, calificada de sesión en algún punto del mismo, en la imposibilidad de realizar una reunión presencial de la Diputación Permanente que garantice la igualdad de participación de todos los grupos parlamentarios; señala que la reunión tendrá carácter informal y se realizará por medios telemáticos, y establece el orden y tiempo del debate, como si de una sesión parlamentaria se tratara, siendo por otra parte transmitida en directo en la web del Parlamento.

Previamente, el día 24 de marzo, la Mesa había acordado solicitar un informe técnico y un informe jurídico sobre las posibilidades de realizar una reunión telemática de la Diputación Permanente. Este último informe destaca la no previsión en el Reglamento de la celebración de sesiones de esta forma; sin que existan referencias expresas a la presencia física (como la viva voz o la intervención desde la tribuna o el escaño que aparecen el Reglamento del Congreso, al informe de cuyos servicios jurídicos alude), ésta se deduce de la regulación de los debates contenida en el Título II, capítulo III. El informe concluye con la necesidad de reforma del Reglamento para la celebración de sesiones no presenciales, algo

7 La Mesa de la Diputación Permanente acordó transferir a la Xunta, de forma inmediata, una partida de 2 millones de euros procedentes del remanente de tesorería de la institución, para contribuir a las necesidades presupuestarias de la pandemia; medidas similares se han adoptado en otros Parlamentos bien con fondos procedentes de remanentes, bien de gastos presupuestados y no ejecutados, como los correspondientes a las indemnizaciones o los desplazamientos de los miembros del Parlamento. 
imposible dado que la Cámara se hallaba disuelta y la carencia de competencias de la Diputación Permanente en la materia. Tras esta afirmación, no obstante, el informe abre la posibilidad, basada en el carácter dúctil del Derecho parlamentario, de celebrar tales sesiones si el acuerdo se adoptase por unanimidad de todos sus miembros.

El informe cita la STC 19/2019 — que destaca el carácter presencial de las reuniones parlamentarias - y la vigencia de los principios de presencia, contacto personal e intercambio directo de opiniones y visiones políticas que conforman la esencia del debate parlamentario. Se cita asimismo a los servicios jurídicos del Congreso de los Diputados y dos informes de los servicios jurídicos del Parlamento de Cataluña, de enero y marzo de 2020, los cuales descartan una habilitación generalizada que posibilite las sesiones no presenciales, «posibilidad no prevista en el derecho parlamentario comparado y contraria a la doctrina constitucional».

La Diputación Permanente (cuya última reunión había sido el 18 de febrero) celebra sesión el día 17 de abril, en la semana que hemos marcado como de reinicio de la actividad parlamentaria, de forma telemática, incluidas en el orden del día proposiciones no de ley en relación con la emergencia de Covid-19, algo inusual en la actividad de un órgano de continuidad con el Parlamento disuelto.

El 21 de abril la Mesa, dadas las circunstancias excepcionales, y declarando que no da lugar a precedente parlamentario, acuerda, con la unanimidad de los miembros de la Diputación Permanente, en aplicación de los principios generales que deben propiciar el derecho de participación política, sin olvidar la debida protección al derecho a la salud de los parlamentarios, la posibilidad de delegar el voto en las reuniones que la Diputación Permanente celebre durante el tiempo que perdure la situación de emergencia sanitaria. A partir del 24 de abril se reúne la DP ya con delegación de voto, para comparecencias y proposiciones no de ley.

Ante los acuerdos adoptados cabe plantearse - como lo hicieron posteriormente otros Parlamentos- en primer lugar si era imprescindible romper, en una Comunidad Autónoma de tan reducida extensión y con facilidad de comunicación, el principio de presencialidad acordando la reunión telemática de la Diputación Permanente de la Cámara, órgano ya de por sí reducido, para luego reunirse con carácter presencial y, a partir del 24 de abril, con voto delegado. De otra parte, tampoco las reuniones informales de los portavoces con el Ejecutivo pueden sustituir a las sesiones parlamentarias debidamente convocadas y celebradas (recordemos la tajante declaración contenida en el art. 67.3 CE), y flaco favor hace a la institución generar confusión entre ambas.

\section{MANTENIMIENTO DE LA ACTIVIDAD POR MEDIOS PRESENCIALES O TELEMÁTICOS}

Los Parlamentos no disueltos se enfrentaron al problema planteado por la emergencia sanitaria para la continuación de su actividad. El examen de las 
medidas adoptadas permite establecer dos grandes grupos: a) aquellos que decidieron -normalmente por entender que el Reglamento no permitía otra opción- mantener su actividad, eso sí, muy reducida, recurriendo no obstante en ocasiones a mecanismos tales como la reunión o la votación telemática; b) los que recurrieron a la suspensión del periodo de sesiones u otros artificios para que entrara en juego la Diputación Permanente, estirando más o menos sus competencias. Dejaremos estos para el final por ser la solución que puede plantear más dudas sobre su corrección jurídica.

En el primer grupo, aquellos que descartaron el dudoso recurso a la Diputación Permanente, se encuentran el Congreso de los Diputados y el Senado y los Parlamentos de las Comunidades Autónomas siguientes: Cataluña, Asturias, Cantabria, La Rioja, Región de Murcia, Aragón, Castilla-La Mancha, Navarra y Madrid, subdivisibles a su vez en dos grupos, según que se celebraran o no sesiones de forma telemática, del Pleno o de las comisiones.

Como se ha señalado, la actividad parlamentaria se redujo a mínimos ${ }^{8}$ al menos durante un mes, celebrándose en todo caso reuniones de la Mesa y a veces de la Junta de Portavoces, presenciales o en general telemáticas por videoconferencia, incluso mixtas ${ }^{9}$; en Castilla y León, que no pertenece al grupo que estudiamos ahora, se delegaron todas las funciones de la Mesa en el Presidente; como regla general, se cerró el Registro general presencial y se habilitó el telemático o por correo electrónico, aunque en algún caso se suspendió durante un tiempo; se suspendieron los plazos de tramitación de iniciativas. En cuanto a las eventuales reuniones de órganos de trabajo, Pleno y comisiones, se optó en general por un formato de asistencia reducida con voto telemático o delegado, según las peculiaridades reglamentarias ${ }^{10}$, y en el peor de los casos con aplicación de voto ponderado.

Veamos brevemente la casuística, cuyo grado de detalle varía en función de la transparencia informativa de cada Parlamento y la publicidad de las normas o acuerdos adoptados ${ }^{11}$ :

- en el Parlamento de Cataluña, el Pleno celebró sesión ordinaria el 3 de marzo; el 13 de marzo, la Mesa acordó la reducción de la actividad a

8 La actividad administrativa se recondujo al teletrabajo, normalmente por acuerdo de la respectiva Mesa, limitándose a los servicios esenciales la presencia física en la sede y acordándose la suspensión de plazos y la supresión del registro presencial. Véanse, por ejemplo, Acuerdos de la Mesa de las Cortes de Aragón de 13 y 16 de marzo de 2020 .

9 Nada que objetar al carácter telemático de las reuniones de los órganos de gobierno de las Cámaras, mucho más frecuentes, que no ejercen funciones atribuidas a aquellas por la Constitución o los Estatutos de Autonomía.

10 Sobre los diferentes sistemas de voto a distancia, P. GARCía-Escudero MárQuez, «Voto parlamentario no presencial y sustitución temporal de los parlamentarios», Corts. Anuario de Derecho Parlamentario, n. ${ }^{\circ} 24,2010$, pp. 87-114.

11 Para la comprobación y actualización de los datos incluidos, ha sido de gran utilidad la consulta al dossier elaborado por la Dirección de Estudios Parlamentarios del Parlamento de Cataluña, accesible en www. parlament.cat. 
sesiones plenarias, sólo con carácter excepcional, con formato reducido a 21 diputados (número de miembros de las comisiones legislativas) y voto delegado. Se suspendieron comisiones y ponencias hasta el 27 de marzo y se habilitó un correo para el registro, prorrogándose 15 días los plazos. Las reuniones de la Mesa se harían telemáticamente en caso de restricción de movimientos de forma general. El 17 de marzo, la Mesa en reunión por videoconferencia, acordó aplazar el Pleno previsto para esa semana, reducido previamente a la convalidación de un decreto ley, y encargar un informe sobre la viabilidad técnica y jurídica de las reuniones telemáticas de órganos parlamentarios.

El informe de los servicios jurídicos de 23 de marzo de 2020 proponía que se descartara la posibilidad de habilitar excepcionalmente sesiones no presenciales del Pleno, sobre la base de la normativa reglamentaria y de la STC 19/2019, referida a esta Cámara, así como por razones tecnológicas y sobre todo por la naturaleza de sus funciones como órgano supremo de la Cámara, admitiendo la reunión no presencial de la Mesa (como ya había previsto este órgano en sus reuniones de 13, 17 y 20 de marzo) y la Junta de Portavoces, así como sesiones informativas o de comparecencia de las comisiones vinculadas a la crisis sanitarias. Asimismo, y de acuerdo con la STC 19/2019, se planteaba la posibilidad de prever en el Reglamento circunstancias excepcionales o de fuerza mayor para el voto en ausencia. Sobre la fórmula acordada por la Mesa el 13 de marzo de celebrar sesiones de Pleno en formato reducido de 21 diputados, fórmula análoga a la del Congreso y el Senado, se descarta el voto telemático por falta de las garantías exigidas por el artículo 95.3 del Reglamento y se prevé autorizar el voto delegado por incapacidad prolongada conforme al artículo 95.2. El informe excluye la posibilidad de suspensión del periodo de sesiones para que entre en funciones la Diputación Permanente, por estar aquellos fijados en el Reglamento y ser limitadas las funciones de ésta, aunque, caso de adoptarse el acuerdo, entiende que se podría regular el ejercicio excepcional de alguna de las funciones que le corresponden en caso de disolución (comparecencias, decretos leyes).

El 20 de marzo, la Mesa, reunida en videoconferencia, acordó por unanimidad habilitar un formato extraordinario para que el Presidente de la Generalidad compareciera telemáticamente (lo haría el 25 de marzo) ante los presidentes de los grupos y subgrupos parlamentarios para explicar las medidas sobre la crisis del coronavirus, formato calificado de sesión presidida por el Presidente del Parlament y retransmitida por el Canal Parlamento; asimismo, se acuerda la celebración telemática de una sesión informativa de la Consejera de Salud ante la comisión correspondiente, así como la reunión telemática de la Junta de Portavoces. El 24 de marzo, la Mesa acuerda la reactivación de la ponencia de reforma del Reglamento, a la que trasladó el informe de los servicios jurídicos que contenía 
propuestas para superar los inconvenientes jurídicos para las reuniones telemáticas.

La actividad se restablece a partir del 6 de abril, con comparecencias de consejeros en formato de videoconferencia ante las distintas comisiones, conforme a acuerdo de la Mesa de 31 de marzo. El 14 de abril, la Mesa y la Junta de Portavoces, reunidas telemáticamente ${ }^{12}$, acuerdan celebrar el día 24 el debate del Proyecto de ley de Presupuestos para 2020 en Pleno presencial con asistencia reducida y delegación de voto o voto telemático, en cuyo orden del día se incluía también la sesión de control y la convalidación de decretos leyes. El 17 de mayo, la Mesa adopta medidas sobre reactivación de la actividad parlamentaria en varias etapas mientras que el 21 de mayo, el Pleno aprueba por unanimidad crear una Comisión de investigación sobre la gestión de las residencias para personas mayores. El 3 de junio se crea una Comisión de estudio para la reconstrucción y la reactivación social y económica.

En el Parlamento de Cataluña vemos una combinación de soluciones que ya hemos observado en otras Cámaras: junto a las informales reuniones informativas con portavoces, la celebración de plenos de asistencia reducida con delegación de voto o voto telemático. Es de alabar el intento de mantenerse dentro de la normativa reglamentaria, aun con una aplicación extensiva de los supuestos de voto a distancia. Ahora bien, si el Pleno de la Cámara se reúne de forma presencial, no se comprende por qué las sesiones de las comisiones no podían adoptar el mismo formato, en lugar de la videoconferencia.

- en Asturias se acordó un Plan de contingencia por Acuerdo de la Mesa de 13 de marzo de 2020, que fue objeto de varias modificaciones posteriores: además de la suspensión de las sesiones de Pleno y Comisión y reuniones de ponencias y Mesas de comisiones — salvo las consideradas absolutamente imprescindibles por acuerdo de la Mesa con el parecer de la Junta de Portavoces_- se acordó la celebración telemática de las reuniones de trabajo. Se constituyó un Grupo de Trabajo formado por los portavoces de los grupos parlamentarios y el Presidente de la Cámara, al que informa el Presidente de la Comunidad en reuniones por videoconferencia «a petición propia», así como los consejeros, de forma continuada a partir del 27 de abril. De nuevo aquí nos encontramos con una cierta confusión - deliberada o no- entre las reuniones parlamentarias y las políticas, sin perjuicio de que reconozcamos la necesidad de establecer canales para la relación Ejecutivo-Legislativo en tiempos de crisis, siempre que no se entienda que ello puede sustituir a la actividad de control parlamentario.

12 El día 20, la Mesa acuerda entregar a la Generalitat 2 millones de euros del remanente presupuestario de 2019 para contribuir a la lucha contra el coronavirus. 
El Pleno celebraría su primera sesión el 6 de mayo (por acuerdo de la Mesa de 28 de abril), con presencia reducida y voto telemático en los términos del acuerdo de 24 de abril ${ }^{13}$, con preguntas, interpelaciones y proposiciones no de ley incluidas en el orden del día. El 20 de mayo, el Pleno aprueba la reforma del artículo 111.2 del Reglamento para ampliar los supuestos de voto telemático a las situaciones excepcionales que impidan la normal presencia de los diputados en la Cámara y posibilitar su aplicación a las reuniones de comisión. El 22 de mayo se constituye una Comisión especial de estudio de la gestión de la crisis sanitaria, social y económica provocada por la COVID-19.

- en el Parlamento de Cantabria, la Mesa acordó el 13 de marzo (BOPC 71) la suspensión de la actividad durante dos semanas —previsión inicial de vigencia del estado de alarma que luego se prorrogaría varias veces, de ahí el acuerdo de continuación de la suspensión adoptado el 27 de marzo, BOPC 75-, con excepción de las reuniones de Mesa y Portavoces. El 6 de abril tuvo lugar una sesión plenaria, con la sola presencia de los portavoces de los cinco grupos parlamentarios, el Presidente y dos miembros de la Mesa, al objeto de celebrar la comparecencia del Presidente del Gobierno y del Consejero de Sanidad, a petición propia, para informar de la gestión de la pandemia en la Comunidad. El mismo Consejero comparecería el 17 de abril en una Comisión especial no permanente constituida para el estudio y seguimiento de la situación, comisión que contemplaba la celebración de dos comparecencias semanales de distintos consejeros. Esta Comisión, creada el 11 abril por la Mesa oída la Junta de Portavoces conforme al artículo 55 del Reglamento, se reunía de forma presencial en el hemiciclo para observar la distancia de seguridad entre sus diez miembros.

La creación de una comisión de este tipo, con un reducido número de miembros, siempre que se observen las normas reglamentarias para su constitución y reunión, podría haber sido una solución a las necesidades de seguimiento e información a que antes se aludía, aunque las comisiones especiales son comisiones de estudio y no realizan actividades ordinarias de control, atribuidas a las comisiones permanentes legislativas.

A partir del 25 de mayo, las sesiones plenarias se celebrarían con presencia reducida y con autorización a todos los diputados del voto telemático regulado por Acuerdo de la Mesa de 15 de junio de 2012.

— en el Parlamento de La Rioja, la Mesa y la Junta de Portavoces acordaron el día 13 de marzo la suspensión de la actividad parlamentaria del 16 al 29 de marzo, prorrogado después hasta el 30 de abril. El día 11, la Mesa

13 El voto telemático estaba regulado por el Reglamento de la Junta General (arts. 111.2 y 107.2) tras la reforma de 5 de febrero de 2020, así como por Acuerdo de la Mesa de 2 de marzo, sobre su articulación, el cual sería sustituido por Acuerdo de 22 de mayo de 2020. 
había aprobado un Plan de Contingencia que fue complementado con posterioridad al acuerdo de suspensión. Se habilitó un registro por correo electrónico confirmado por teléfono con el autor para verificar la exactitud e integridad de la iniciativa presentada.

El 14 de abril, se aprobó una Resolución de la Presidencia sobre reuniones telemáticas de las comisiones durante la situación de crisis sanitaria generada por el coronavirus (BOPR n. ${ }^{\circ} 270$ ), con el fin de posibilitar la función de control de la acción política y de gobierno que corresponde al Parlamento. Conforme a la Resolución — cuya exposición de motivos cita el artículo 60.2 del Reglamento del que se deduce la reunión presencial: discursos pronunciados personalmente y de viva voz desde la tribuna o desde el escaño-, mientras durara la crisis sanitaria, las comisiones podrían mantener reuniones telemáticas para celebrar comparecencias informativas de los miembros del Gobierno de la Rioja sobre cuestiones relacionadas con aquella, convocadas y presididas por el Presidente de la Cámara, y con la asistencia del Consejero y hasta un máximo de dos responsables de su departamento, así como de un portavoz de cada grupo parlamentario y un letrado que redactaría y firmaría el acta con el visto bueno del Presidente, asistidos por un técnico; la votación — que no se alcanza por qué habría de darse en una sesión informativa - se haría por el mismo sistema informático que la reunión, sin posibilidad de voto secreto; la Resolución regula el desarrollo y aplazamiento de las sesiones. Distintos Consejeros comenzaron a comparecer a partir del 16 de abril por medios telemáticos ante los portavoces de los grupos parlamentarios en las comisiones permanentes competentes, conforme al calendario asimismo aprobado el 14 de abril por la Mesa de conformidad con la Junta de Portavoces (BOPLR n. ${ }^{\circ}$ 128). De otra parte, se celebrarían reuniones informativas de consejeros con la Junta de Portavoces, asimismo en régimen de videoconferencia, para lo que se remitiría la correspondiente invitación por correo electrónico.

Comentario a la Resolución: a diferencia de supuestos anteriores, en los que hemos criticado que reuniones no parlamentarias sustituyeran a las parlamentarias, en este caso lo que puede censurarse es que, contra la letra del Reglamento, se permita, mediante una norma interpretativa/supletoria (pues otras no existen) del Reglamento, celebrar sesiones no presenciales. En su favor ha de decirse que al menos se han mantenido las formalidades precisas - convocatoria, acta-; en su contra, aparte lo ya señalado, que se prevea la votación para reuniones informativas. Se entiende que ésta, no obstante, se realizaría por videoconferencia, o sea, cabe entender que expresando el sentido de la votación de viva voz, lo que sería coherente con el criterio no presencial adoptado.

El 28 de abril, la Mesa y la JP acuerdan que a partir del 2 de mayo y mientras se prolongue el estado de alarma, se celebren sesiones presenciales 
con la asistencia de 12 parlamentarios en Pleno y la totalidad de los miembros de comisiones, siempre en el salón de sesiones y observando la distancia debida; en el orden del día de las sesiones plenarias se incluirían preguntas orales y comparecencias del miembros del Gobierno (BOPR 136). El 7 de mayo se celebra el primer Pleno. El 29 de mayo (BOPR 155), la Mesa y la Junta de Portavoces acuerdan por unanimidad que la adopción de acuerdos por el Pleno mientras dure el estado de alarma se realice mediante voto ponderado, lo cual es criticable por razones obvias: si los portavoces pueden sustituir a los parlamentarios en Pleno, cabe suprimir la institución.

- en la Asamblea Regional de Murcia, la Mesa acordó el 12 de marzo un Plan de contingencia en el que se señalaba que las medidas adoptadas no afectaban en principio a la actividad parlamentaria prevista, que desarrollarían los diputados con el personal imprescindible para el desarrollo de las sesiones. El 16 de marzo, la Junta de Portavoces —reunida en el Salón de Plenos para observar la distancia de seguridad — acordó aplazar la actividad parlamentaria hasta el 31 de marzo; la Mesa acordó que el Registro siguiera abierto. En realidad, la paralización se prolongó: el 14 de abril, la Junta acordó reanudar la actividad con la reunión el día 20 de la Comisión de Economía, Hacienda y Presupuesto. El día 21 se celebraría sesión plenaria para la convalidación de un decreto-ley, así como para el debate y votación del proyecto de Ley de Presupuestos para 2020, con asistencia reducida a 17 diputados y el Presidente de la Comunidad y voto ponderado. Los días siguientes se celebrarían comparecencias del Presidente y la Vicepresidenta del Gobierno Regional ${ }^{14}$.

Un informe de la Secretaría General, de 22 de abril, en relación con la petición del Grupo parlamentario Ciudadanos de que toda la actividad parlamentaria se realizara por medios telemáticos y de que esta petición se sometiera a votación de los grupos parlamentarios, de forma que, si se aceptara por unanimidad, se buscara «la forma jurídica oportuna desde la excepcionalidad que requiere la situación» concluye que, a la vista de la prohibición contenida en el artículo 90 del Reglamento (según el cual «Los discursos se pronunciarán personalmente y sin interrupción, sin que estén permitidas las intervenciones de las diputadas y los diputados ausentes de la Cámara por medios telemáticos o mediante videoconferencia»), además de otras referencias a la presencia, y de la doctrina del TC, no existe posibilidad jurídica (ni técnica, no estando además disponibles los medios para la emisión de voto telemático) que permita celebrar reuniones de pleno y comisiones no presenciales en la Asamblea Regional, sin que las normas

14 Una Comisión especial de estudio sobre el Plan de reactivación económica y social se constituyó el 18 de mayo. 
que afectan a elementos esenciales en la ordenación y desarrollo del funcionamiento de la Cámara sean susceptibles de ser ignoradas o evadidas simplemente con una votación, siendo necesaria en su caso una reforma. El informe recoge los ejemplos de Derecho comparado y de otros Parlamentos autonómicos, así como el único caso del Reglamento del Parlamento balear, cuyo artículo 90.3 y 4 permite celebrar reuniones no presenciales de las Mesas de las comisiones y de éstas, excepto para los debates legislativos, circunscrita a los diputados de las islas menores y previa autorización de la Mesa, por las especiales características de la insularidad.

El principal punto débil de estos acuerdos es que, no permitido el voto por delegación, aunque sí el voto a distancia (art. 103.2 RARM) por videoconferencia u otros medios, y acordado que el número de diputados asistentes se redujera, el voto sería ponderado, lo cual quiebra el principio de personalidad e indelegabilidad del voto, al menos salvo que en la normativa reglamentaria se establezca otra cosa, como ocurre cuando se regula el voto por delegación (siempre que el Estatuto no lo prohíba reproduciendo el artículo $79.3 \mathrm{CE}$, según el cual el voto de diputados y senadores es personal e indelegable, que por otra parte recoge el artículo 99.1 del RARM). Parece que el obstáculo a la utilización del voto telemático se encontraba en la falta de regulación de desarrollo y de implementación técnica.

— en las Cortes de Aragón se acuerda por la Mesa el 16 de marzo «formato de Diputación Permanente» para Pleno y presencia solo de portavoces en comisión (en realidad, las sesiones de comisión se reanudaron por videoconferencia a parir del 17 de abril), con adopción de acuerdo por voto ponderado en ellas, lo cual supone una extensión de lo previsto en el Reglamento, a la vez que la vulneración de las reglas sobre quórum en comisiones. En esta Comunidad, su Presidente celebró varias reuniones telemáticas informativas con diputados, siendo la primera comparecencia en Pleno el 15 de abril, reunido también para la convalidación de un decreto-ley (formato reducido a 24 diputados, presencia de 16 más Presidente y dos miembros de la Mesa, y emitiéndose 7 votos telemáticos). El 8 de abril se había modificado por Resolución de la Presidencia la Resolución de 31 de octubre de 2018, por la que se regula la emisión de voto no presencial, para ampliar los supuestos de autorización posible incluyendo las causas que impliquen riesgo constatable para la salud e integridad de los diputados (BOCA 51).

- en las Cortes de Castilla-La Mancha, el último Pleno antes de la declaración del estado de alarma tuvo lugar el 12 de marzo, sesión en la que se sometió a votación su aplazamiento, que fue rechazado. El 23 de marzo, la Mesa y la Junta de Portavoces se reunieron de forma telemática para convocar la Comisión de Sanidad para el día 26 por videoconferencia (D. de S. 42). El 
30 de marzo la Mesa acordó por unanimidad recuperar la actividad en suspenso durante los meses de verano. El 6 de abril, acordó reactivar la actividad parlamentaria el día en que se levantara el estado de alarma, atendiendo a informes de los servicios jurídicos en el sentido de que el Reglamento impedía la convocatoria de plenos y comisiones por vía telemática. El 2 de mayo, excepcionalmente se celebraría una sesión plenaria con formato reducido a 18 diputados, con la comparecencia del Presidente y el Consejero de Sanidad. El 8 de mayo, la Mesa acuerda establecer un calendario de comparecencias de los consejeros ante las comisiones como primer paso para la recuperación de la actividad normal, en un segundo momento, con sesiones plenarias ordinarias. El 4 de junio se reanuda la actividad del periodo de sesiones con el primer Pleno, tras la reunión presencial de la Mesa y el levantamiento de la suspensión de plazos de iniciativas legislativas. El 18 de junio, el Pleno aprueba una modificación del Reglamento (nuevo art. 84 bis, arts. 89 y 111) para habilitar la celebración de sesiones plenarias por videoconferencia (BOCCM 54) en los estados previstos en el artículo 116 $\mathrm{CE}$ o en situaciones de imposibilidad material de celebrar sesión sin poner en riesgo la integridad de diputados y personal, apreciada por la Junta de Portavoces por mayoría de tres quintos.

- en el Parlamento de Navarra, el 12 de marzo de 2020 la Mesa, oída la Junta de Portavoces, acordó aprobar el Plan de Contingencia ante el Coronavirus, entre cuyas medidas a aplicar desde el día 16 se encontraba la suspensión de las reuniones de trabajo en comisión y de la asistencia de público a las sesiones plenarias. El 16 de marzo se aprobaron medidas extraordinarias, que fueron prorrogadas el 27 de marzo y el 8 y 24 de abril, como son el cierre del edificio y de todos los servicios, el registro oficial telemático y por correo electrónico para resto de interesados, la suspensión de la tramitación y de plazos, así como la restricción de los trabajos parlamentarios a reuniones de Mesa y Junta de Portavoces - prioritariamente mediante videoconferencia- y a posibles sesiones concretas de otros órganos (previendo en primer término del Pleno, así como de la Comisión de Régimen Foral en reunión semanal para seguimiento, con comparecencia del Gobierno y asistencia de un representante por grupo) por razones de urgencia inaplazables. Estos acuerdos se basan, según la web del Parlamento, en informes de los servicios jurídicos que certifican, en relación al ejercicio de las funciones parlamentarias imprescindibles durante el periodo de restricción, la posibilidad de celebrar sesiones urgentes y seguras con voto delegado. En este marco, una Resolución de la Presidencia de 25 de marzo, adoptada por la Mesa con el acuerdo vinculante de la JP, incluyó entre los supuestos de delegación de voto previstos en el art. 94.2b) del Reglamento (hospitalización o enfermedad grave) los asociados a riesgo para la salud en situaciones de crisis sanitarias y restricción de la actividad de la Cámara. 
Se celebran Plenos los días 27 de marzo y 3, 8 y 21 de abril para la convalidación de decretos-leyes, su tramitación por lectura única y la aprobación de proyectos de ley relacionados con la crisis de la COVID-19. Sin presencia de medios de comunicación y con la asistencia de miembros de la Mesa, los portavoces de los seis grupos parlamentarios y miembros del Gobierno, el resto de parlamentarios emitió su voto por delegación. El 24 de abril, la Mesa acuerda encomendar a los servicios generales la puesta en marcha de las medidas necesarias para el desarrollo de las sesiones de los órganos del Parlamento por medios telemáticos. El 30 de abril tiene lugar la primera sesión de control del Gobierno, con lo que desaparece el procedimiento excepcional de control, información y documentación escrita articulado en torno a la Comisión de Régimen Foral. La Mesa, oída la JP, aprueba el 8 de mayo (BOPN 51) un Plan de Contingencia relativa al retorno a la actividad presencial (modificado el 1 de junio, BOPN 64) en el que se prevé a partir del día 18 la reanudación de la actividad parlamentaria con posibilidad de reunión de los órganos en sesión presencial, no presencial y mixta por videoconferencia, planteándose el aumento de las sesiones telemáticas de comisión con voto público por llamamiento y Plenos presenciales con asistencia reducida. El 18 de mayo, la Mesa acuerda unas Instrucciones para la celebración de las sesiones telemáticas del Pleno y las comisiones (BOPN 56). El primer Pleno presencial y telemático se celebra el 21 de mayo.

Los acuerdos en el seno de este Parlamento son al principio similares a los adoptados en el Congreso de los Diputados, sobre la base de normativa reglamentaria diferente para el voto a distancia: voto delegado en el caso de Navarra y telemático en el Congreso. En ambos se amplían los supuestos previstos en el Reglamento por analogía con la situación de emergencia sanitaria, en el caso de Navarra con el añadido de que se realiza mediante una Resolución de la Presidencia, lo que contribuye a la seguridad jurídica. La ampliación analógica, que podría ser censurable, en las circunstancias de la magnitud a la que se aplicaban creemos constituye un mal menor frente a otras soluciones claramente antirreglamentarias como algunas expuestas o a exponer. En un momento posterior, se opta por las sesiones telemáticas, decisión menos ortodoxa.

— en la Asamblea de Madrid, el 11 de marzo la Mesa acordó suspender toda la actividad parlamentaria por quince días, suspensión que afectaría también a las reuniones de Mesa y Junta de Portavoces, salvo que fuere necesario proceder a su convocatoria, así como la prórroga de los plazos en curso por el tiempo de la suspensión (BOAM 44); cerrada la Cámara a partir del 13 de marzo, se establece la solicitud de registro por correo electrónico, resolviendo la Mesa telefónicamente sobre la concurrencia de circunstancias excepcionales y de urgente necesidad que justificaran la formalización del escrito en el Registro, no obstante la suspensión de la actividad parlamentaria acordada (BOAM 44). 
Por acuerdo de la Mesa, oída la Junta de Portavoces, en reunión telemática de 11 de abril de 2020 (BOAM 46), se levanta la suspensión de la actividad parlamentaria y se acuerda su reanudación gradual, circunscrita a los asuntos vinculados con la crisis de la Covid-19, manteniendo la suspensión del resto de plazos y suspendiendo el calendario de sesiones en tanto durara el estado de alarma. Se reanuda la celebración de reuniones de la Mesa (semanales por vía telemática) y la JP, así como de las Comisiones para la tramitación de comparecencias, de forma acumulada y preferentemente por vía telemática, una por sesión, comenzando con la Comisión de Sanidad, transmitiéndose por el canal de la asamblea y medios interesados. Si la conexión técnicamente no garantizara un correcto desarrollo de la sesión, se analizaría la convocatoria de reuniones presenciales. Se abre el registro telemático. Por acuerdo de 20 de abril se realiza la ordenación de la reanudación de la actividad parlamentaria sobre asuntos vinculados al Covid-19 y por acuerdo de 25 de abril se prorroga el de 11 de abril sobre la actividad parlamentaria, prorrogado también con modificaciones por Acuerdo de 23 de mayo, con previsión de reuniones semanales de Pleno y comisión; asimismo se regula el carácter presencial de las comisiones, con presencia reducida (BOAM 48). El 27 de abril se levanta parcialmente la suspensión de plazos administrativos en la contratación y se mantiene la actividad administrativa ordinaria. El 9 de junio se aprueban medidas para la reactivación de la actividad parlamentaria (BOAM 57), con presencia de 70 diputados en Pleno y de 12 - posteriormente 20 - en comisión, levantándose la suspensión de la calificación de iniciativa no relacionadas con la crisis del Covid-19, si bien no se tramitarían hasta el fin del estado de alarma. El 16 de junio se crea una Comisión de investigación sobre los centros residenciales de personas mayores.

La crítica a los acuerdos adoptados es la efectuada ya antes, en relación con la celebración de sesiones telemáticas de comisiones o pleno, sin cobertura reglamentaria. De hecho, convocada sesión plenaria de control a celebrar por esta vía telemática el día 23 de abril, hubo de suspenderse apenas iniciada por imposibilidad de conexión desde los primeros minutos; aunque se planteó la reanudación presencial esa misma tarde, tuvo lugar al día siguiente (a partir de entonces se celebraron sesiones semanales). No es que este incidente constituya un argumento en apoyo de la tesis de fondo, pero sí nos recuerda que el Parlamento está concebido como asamblea de personas y sus medios técnicos responden a esta cualidad, de modo que cuando pretende obviarse el carácter presencial no sólo no existe apoyo técnico suficiente con antelación, sino que puede plantear problemas de garantías de autenticidad. De otra parte, la experiencia ha ratificado que las innovaciones han de ser comprobadas antes de ponerse en práctica.

\section{ACTIVACIÓN DE LA DIPUTACIÓN PERMANENTE}

Un segundo grupo de Parlamentos autonómicos, de las Comunidades Autónomas de Andalucía, Valenciana, Castilla y León, Extremadura, Canarias y Baleares, 
ha optado por la activación de la Diputación Permanente durante la vigencia del estado de alarma o parte de ella. Esta solución es la más criticable, sobre la base del propio carácter de dicho órgano de continuidad, llamado a sustituir al Pleno cuando éste no puede reunirse — por razones jurídicas preestablecidas y tasadas, no fácticas- y con unas funciones mínimas. La extensión de unas y otras entraña un peligro evidente: ¿por qué no sustituir con carácter ordinario los órganos de trabajo del Parlamento por una representación reducida limitada a los portavoces de los grupos parlamentarios? ${ }^{15}$ Ello puede llevarse al extremo en los casos en que en la propia disminuida DP se actúa con voto ponderado, incluso con una previsión reglamentaria insólita, como ocurre en la Asamblea de Extremadura. Como veremos, en algunos casos la escasa actividad de la DP y el retorno a la reunión de los órganos ordinarios con formato reducido y voto no presencial revelan que la primera decisión adoptada fue precipitada y que tal vez podría haberse evitado.

Aquí también recogeremos las variantes y su crítica:

— en el Parlamento de Andalucía, la Mesa acordó el 16 de marzo de 2020 adaptar la actividad parlamentaria de la Cámara a la declaración del estado de alarma, con suspensión de las sesiones previstas y de los plazos de tramitación de las iniciativas parlamentarias, así como del registro de iniciativas ordinarias, incluidas las de control del Gobierno; «a efectos de continuar con la actividad parlamentaria indispensable», se convocaría la Diputación Permanente de conformidad con lo dispuesto en el artículo 57.3 del Reglamento ${ }^{16}$. El 18 de marzo se aprobó una Resolución de la Presidencia sobre habilitación de la convocatoria de la DP, adoptada con el acuerdo unánime de los miembros de la Mesa y de la Junta de Portavoces, expresada por vía telemática. La Diputación se convoca para el 25 de marzo con el fin de sustanciar por esta misma vía tres comparecencias de miembros del Consejo de Gobierno, planteándose durante la sesión la procedencia de su convocatoria y sus competencias. El 23 de marzo, reunida

15 La STC 19/2019 declara: «La exigencia de que la función parlamentaria se ejerza en un determinado espacio físico - la sede del Parlamento - no tiene solo como finalidad garantizar que los parlamentarios puedan ejercer su función representativa en un lugar en el que no puedan ser perturbados, sino que cumple también una función simbólica, al ser ese el único lugar en el que el sujeto inmaterial que es el pueblo se hace presente ante la ciudadanía como unidad de imputación y se evidencia la centralidad de esta institución». Esta observación puede aplicarse también a la sustitución del Pleno por otro órgano. Se dirá que los Plenos con asistencia reducida afectan también a su carácter simbólico, pero al menos es el órgano representativo supremo que ejerce todos los poderes de la Cámara el que intenta mantener su presencia y ejercer sus funciones. Podría parecer que no todos los Parlamentos han recordado el carácter simbólico de la reunión presencial en la sede.

16 El art. 58 declara expresamente que la DP velará por los poderes de la Cámara «cuando el Parlamento no esté reunido por vacaciones parlamentarias [expresión coloquial que no debía figurar en una norma jurídica], cuando haya sido disuelto o haya expirado el mandato parlamentario y hasta tanto se constituya el nuevo Parlamento». «Especialmente» se citan las funciones de convocar el Pleno o las comisiones y conocer de la delegación temporal de las funciones ejecutivas propias del Presidente de la Junta o de un miembro del Consejo de Gobierno. 
telemáticamente, la Mesa acuerda solicitar un informe sobre la procedencia de la convocatoria de la Diputación Permanente durante la vigencia del estado de alarma.

El informe de los servicios jurídicos, de 27 de marzo de 2020, considera que existe una laguna jurídica respecto del funcionamiento del Parlamento en situación de grave crisis sanitaria que ocasiona la necesidad de suspender la actividad parlamentaria, que puede cubrirse por analogía con la regulación del supuesto más cercano, siendo tal el denominado de «vacaciones parlamentarias» porque en él también se produce la necesidad de la suspensión. Entiende, por tanto, que la convocatoria de la DP es una medida idónea para garantizar la continuidad de la actividad parlamentaria en supuestos de suspensión de las sesiones de los órganos de la Cámara por fuerza mayor derivada del riesgo para la salud en crisis sanitaria. Se aplica también el principio general de la continuidad de la actividad del Parlamento, siendo el instrumento para dicho fin en nuestra cultura jurídica la DP, concluyendo en la conformidad con el Estatuto de Autonomía y con el Reglamento del Acuerdo y la Resolución sobre habilitación de la convocatoria de la DP en una situación de declaración del estado de alarma.

El informe se cuestiona las alternativas adoptadas por otros Parlamentos, como los plenos de asistencia reducida y su carácter artificioso cuando sólo están presentes los portavoces, o la pura y simple suspensión de la actividad, y cita en apoyo de la solución adoptada los informes emitidos en Cataluña y Canarias.

En cuanto a la posible competencia de la DP para convalidar decretos-leyes, el informe considera diferente la regulación del artículo 78.2 CE (que sólo atribuye a la DP esta competencia en caso de disolución) de la establecida por el artículo 103.4 del Estatuto de Autonomía, que remite al Reglamento la composición y funciones de la DP, habiendo sido reguladas estas por Resolución de la Presidencia de 5 de junio de 2008, sobre control por el Parlamento de los decretos-leyes dictados por el Consejo de Gobierno. Esta Resolución permite la convalidación por la DP tanto entre periodos de sesiones como cuando el Parlamento esté disuelto o extinguido su mandato.

A mi juicio, la cuestión polémica no se halla en si la DP puede convalidar o no decretos leyes entre sesiones, resuelta por norma supletoria en este Parlamento (aunque habría sido más correcta una reforma del Reglamento), sino en si puede convocarse la Diputación Permanente en una situación como la existente, sin norma que lo ampare y aplicando una analogía dudosa. Creo que no existía imposibilidad de reunión de órganos parlamentarios, sino riesgo sanitario, que por otra parte podía ser más elevado en una Comunidad Autónoma como Andalucía, cuyo número de parlamentarios se encuentra entre los que superan los cien (aún así, una tercera parte de los miembros del Congreso y menos de la mitad de los miembros del Senado, Cámaras que no podrían constituir términos 
adecuados de comparación) y con un ámbito territorial asimismo grande. Esta observación no sería aplicable a las Comunidades Autónomas uniprovinciales, por ejemplo.

No obstante, si la DP puede reunirse y ello no se discute, si además lo hace por vía telemática, y si cabe la posibilidad de delegación de voto (art. 85.1, 5 y 6 RPA) y de voto telemático (art. 85.7 RPA) y su aplicación - analógica si se quiere- al supuesto actual, parece menor retorcimiento de la normativa la convocatoria de los órganos ordinarios para los que aquélla está prevista, teniendo en cuenta que, de acuerdo con el artículo 85.6 RPA, es la Mesa la competente para establecer los criterios generales para determinar los supuestos que determinen la delegación, hasta ahora regulados por Acuerdo de la Mesa de 1 de junio de 2016.

Yendo al terreno de los hechos, la Diputación Permanente se reunió en sesión telemática el 25 de marzo para la comparecencia de tres consejeros; presencial los días 2, 16 y 24 de abril para la convalidación de decretos-leyes y la comparecencia de consejeros. Por las razones expuestas, habría sido más fácil jurídicamente, si al final las reuniones de la DP para votación habían de ser presenciales, convocar el Pleno, aun con formato reducido en cuanto a la presencia. Este sería el criterio adoptado cuando el 14 de abril la Mesa se plantea la reanudación de la actividad del Pleno y las comisiones en sesiones de control, previa reforma del Reglamento para ampliar los supuestos de delegación de voto. El 29 de abril se deja sin efecto la habilitación de la DP y se acuerda retomar dicha actividad circunscrita fundamentalmente, en tanto rigiera el estado de alarma, a iniciativas relacionadas con la Covid-19, comenzando con una sesión plenaria el 6 de mayo con formato reducido a 44 diputados y voto delegado en el portavoz para los no presentes (BOPA 316). En ese primer Pleno, con preguntas orales y comparecencias, se aprobaría en lectura única la reforma del Reglamento para añadir un artículo 90 bis sobre el voto delegado en situaciones excepcionales ${ }^{17}$ (BOPA 320) — modificado para extenderlo a las comisiones el 3 de junio ${ }^{18}$ (BOPA 342), cuyo acuerdo de aplicación de misma fecha se deja sin efecto el 1 de julio (BOPA 361) — y se crearía una Comisión de estudio sobre la recuperación económica y social. El 19 de mayo, la Mesa aprueba las Normas de administración electrónica del Parlamento (BOPA 333). En la sesión plenaria de 20 de mayo, se vota

17 Art. 90 bis: «Los diputados y diputadas, en tanto existan medidas de confinamiento y/o de distancia de seguridad entre personas consecuencia de pandemias u otras situaciones de excepcional gravedad, podrán delegar su voto en otro diputado o diputada». Este precepto, cuyo carácter ad hoc e incluso transitorio se trasluce en su redacción, debería haberse incluido en el artículo 85, entre los supuestos que permiten la delegación del voto.

18 Sendos acuerdos de la Mesa de 13 de mayo y 3 de junio regulan el procedimiento para ejecutar la delegación en el Pleno y las comisiones (BOPA 342). 
presencialmente en dos salas simultáneamente. El 27 de mayo (BOPA 337), se adopta un acuerdo sobre recuperación de la actividad con asistencia reducida. Las sesiones plenarias de dos días se retomarían la primera semana de junio.

Resulta fácil hacer la crítica a posteriori, pero al final el resultado ha sido el mismo que en aquellos Parlamentos que no han recurrido a la DP en un primer momento forzando la normativa: formato reducido y voto por delegación, con lo cual aquello podía haberse evitado.

- en las Cortes Valencianas, la Mesa, de acuerdo con la Junta de Síndics, acordó el 12 de marzo de 2020, con carácter excepcional y transitorio, suspender determinadas reuniones de comisiones previstas ese mes y valorar en su siguiente reunión la celebración del resto, así como la prórroga de plazos. El día anterior se había desconvocado la sesión ordinaria del Pleno para el mismo día 12, celebrándose la comparecencia del Presidente del Consejo para informar de la situación derivada del coronavirus. El 19 de marzo, la Mesa acordó (BOCV n. ${ }^{\circ}$ 71) suspender el período ordinario de sesiones en curso durante la vigencia del estado de alarma (teniendo en cuenta que en su momento había fijado las fechas de inicio y fin del mismo), con la consiguiente suspensión de la tramitación de todas las iniciativas, así como del cómputo de plazos de tramitación; «durante la vigencia del estado de alarma velará por los poderes de la Cámara la Diputación Permanente, de conformidad con lo que establece el artículo 59.1 del $\mathrm{RCV}$ ». Asimismo se acuerda, siempre que sea posible, la celebración de las reuniones de la Mesa y la Junta de forma no presencial y, en su caso, que finalizado el estado de alarma y las circunstancias que motivan el acuerdo, la Mesa, de acuerdo con la Junta de Síndics, pueda habilitar el mes de julio para celebrar sesiones de pleno y comisiones.

El 17 de abril se aprueba una Resolución de la Presidencia sobre la ampliación de supuestos de voto a distancia en las sesiones de la Diputación Permanente durante la declaración del estado de alarma (BOCV n. ${ }^{\circ}$ 74), para que «durante la vigencia del estado de alarma...la Mesa de las Corts Valencianes pueda realizar una interpretación extensiva del sistema de votación telemática o a distancia reconocido en el inciso $5 .^{\circ}$ del artículo 82 del RCV y desarrollada por la Resolución de Presidencia 4/ IX». La Resolución contempla supuestos de sustitución en los debates, sin perjuicio del voto a distancia del titular. El número de diputados presentes en el hemiciclo se limita a 23, 5 miembros de la Mesa y 18 diputados de acuerdo con las cuotas fijadas para los grupos parlamentarios, además en su caso de los miembros del Consell. El voto a distancia se emite por correo electrónico, que puede ser anulado con autorización de la Mesa en caso de asistencia presencial. Los votos a distancia computan a efectos de quorum. La Diputación Permanente se reunió los días 22 y 23 de abril. 
El 28 de abril, la Mesa, de acuerdo con la Junta de Síndics (BOCV 75), acuerda mantener la vigencia del acuerdo de suspensión del periodo ordinario de sesiones con modificaciones, incluida la creación de una Comisión delegada de la DP para sesiones informativas, de composición variable y con voto ponderado. El 5 de mayo (BOCV 76), apenas una semana después del acuerdo anterior previsto para medio plazo y la víspera de autorizarse la cuarta prórroga del estado de alarma, la Mesa y la Junta de Sindics acuerdan reanudar, a partir del lunes 11 de mayo de 2020, el periodo ordinario de sesiones y dejar sin efecto los acuerdos anteriores, lo que supone la reactivación de la tramitación de las iniciativas y del cómputo de los plazos. Las sesiones presenciales de órganos parlamentarios quedarían limitadas a un máximo de tres días por semana, celebrándose en el hemiciclo o telemáticamente si así lo decidiera la Mesa de acuerdo con la Junta. Las sesiones del Pleno se celebrarían con la asistencia de un número reducido de diputados, conforme a lo que se estableciera mediante una resolución de la Presidencia de carácter general en la que también se regularía, para esta situación excepcional, el voto a distancia para los miembros de la Cámara que no asistan presencialmente. Las reuniones de la Mesa de las Corts, las mesas de las comisiones y la Junta de Síndics serían telemáticas salvo que resultara necesario que fueran presenciales. Cuando un miembro del Consell asistiera a una sesión parlamentaria podría acompañarle, como máximo, una persona de su equipo. Una Resolución de la Presidencia de 12 de mayo (BOCV 78) sobre la celebración de sesiones plenarias y de comisiones en situaciones excepcionales establece la asistencia reducida y la posibilidad de sesiones plenarias con participación telemática en número limitado y voto a distancia mediante correo electrónico, así como sesiones de comisión presenciales con voto asimismo a distancia. Una Comisión especial de estudio para la recuperación social, económica y sanitaria se constituye el 15 de mayo, aprobada por la DP en su última reunión. El 19 de mayo la Mesa acuerda la prórroga del periodo de sesiones hasta el 6 de agosto (BOCV 80).

En la sesión plenaria del 25 de mayo se incluye en el orden del día el dictamen sobre el Proyecto de ley de regulación del juego y prevención de la ludopatía, habiéndose acordado por los grupos su votación por voto ponderado. De este acuerdo se retira VOX, aplazándose la votación hasta el día 28, ya de forma telemática. El 26 de mayo y el 9 de junio se actualiza el acuerdo de adaptación de la actividad parlamentaria de 5 de mayo (BOCV 81 y 85). Una Resolución de la Presidencia de 9 de junio (BOCV 85 ) sustituye a la anterior y permite el voto ponderado en pleno cuando así lo acuerde por unanimidad la Junta de Síndics, y la asistencia telemática a las comisiones. El 18 de junio, la Mesa y la JP acuerdan la actualización de las medidas para el desarrollo de la actividad parlamentaria (BOCV 87), modificadas el 7 de julio (BOCV 91). 
El comentario en este caso es evidente. Si en realidad lo que se produjo fue una paralización de la actividad parlamentaria durante la declaración del estado de alarma y la primera prórroga, y cuando ya en todos los Parlamentos se había acordado retomar la actividad la reunión de la DP habría de tener lugar con la asistencia limitada a sus miembros y con voto a distancia, habría sido más correcto no habilitar este órgano, sino celebrar reuniones del Pleno, si se desea con una asistencia reducida y la misma ampliación de voto a distancia que se acordó para la Diputación. El acuerdo de 28 de abril contribuye a la confusión al crear una Comisión Permanente de la DP, integrada o no por miembros de la misma, que se reúne presencial o telemáticamente con debate según las reglas de comisión y dirigido por la mesa de la competente, con aprobación de proposiciones no de ley por voto ponderado condicionada a su ratificación por aquella — siendo de por sí inusual que la DP tramite PNLs—. Combinación de ingredientes extraños, sin justificación real ni apoyo reglamentario, que fue rectificada una semana después con la reactivación de los órganos ordinarios, presencial en formato reducido y telemática, y con voto a distancia o telemático.

- en la Asamblea de Extremadura, el 15 de marzo en reunión por videoconferencia la Mesa acordó (BOAE 143) suspender la actividad parlamentaria durante la duración del estado de alarma, así como los plazos de tramitación, el registro de iniciativas ordinarias, incluidas las de control al Gobierno, y convocar la Diputación Permanente de conformidad con lo dispuesto en el artículo 111.1 del Reglamento en los casos que proceda. Se habilita un correo electrónico para el registro de iniciativas.

La DP se reúne el 19 de marzo para la comparecencia del Vicepresidente segundo y Consejero de Sanidad y Servicios Sociales. El 14 de abril, en reunión presencial, la Mesa acordó el calendario para las semanas siguientes, incluyendo la reunión de la DP los días 20 y 23 de abril. El 21 de abril, la Mesa en reunión telemática acordó celebrar las reuniones de los órganos ordinarios con presencia reducida: la JP (Mesa y un portavoz por grupo, también para reuniones telemáticas), las comisiones (presenciales con Mesa y un portavoz por grupo con voto ponderado), Plenos (presenciales para iniciativas de control con representación de 25 diputados, distribuidos a los grupos parlamentarios según su tamaño; el voto del resto de diputados sería delegado en los portavoces de cada grupo). Se acuerda asimismo la apertura del registro presencial a partir del 24 de abril. El día 30 se celebra la primera sesión plenaria para preguntas y convalidación de decretos-leyes. La reanudación de la presentación de iniciativas parlamentarias se acuerda el 27 de mayo (BOAE 184) — se decide ampliar a 31 el número de diputados que asistirán a la siguiente sesión plenaria, que pasarían a 34 por acuerdo de 9 de junio (BOAE 194) - y el alzamiento de la suspensión de plazos parlamentarios y administrativos el 2 de junio (BOAE 186). 
Aparte de la escasa justificación del recurso a la DP, cabe criticar en el acuerdo adoptado el 21 de abril el voto ponderado en comisión. No hay razones que avalen la necesidad de la ponderación, contraria al principio de personalidad e indelegabilidad del voto salvo previsión estatutaria o reglamentaria. Cierto que el artículo 111.3 RAE establece el voto ponderado para la adopción de las decisiones de la DP (lo cual ya es en sí criticable, por tratarse de un órgano de trabajo de composición proporcional al Pleno que asume las funciones de la Cámara cuando esta no está reunida o disuelta), razón probable por la que se recurrió a la convocatoria de este órgano. Pero la previsión reglamentaria del voto por delegación y voto telemático en el artículo 142 no indica el órgano para cuyas reuniones puede ejercerse, lo que podría hacer sencilla su adopción para las comisiones. Y tampoco parece que fuera a ser necesaria ni conveniente la tramitación en comisión de las iniciativas que requieran votación durante la situación que impide la reunión presencial.

El 6 de mayo se constituye una Comisión no permanente de estudio sobre la pandemia en la CA, creada el día anterior por la Mesa y la Junta al amparo del artículo $108 \mathrm{RAE}$, compuesta por una Mesa (Presidente de la Asamblea y dos miembros de su Mesa) y dos miembros variables por cada grupo, asistiendo representantes del Gobierno regional. Se reuniría en sesiones no públicas con voto ponderado y vigencia prorrogable hasta el fin del periodo de sesiones. En este caso, el voto ponderado no es insólito por tratarse de una comisión de estudio cuya composición no refleja la de la Cámara.

— en las Cortes de Castilla y León, el 13 de marzo de 2020 (BOCCL 93) la Mesa acuerda la suspensión de la actividad parlamentaria del periodo de sesiones en curso, de términos y plazos: «Durante el periodo de suspensión de la actividad parlamentaria velará por los poderes de la Cámara la Diputación Permanente». Por Resolución de la Presidencia de 16 de marzo de 2020 (BOCCL 93), se habilita el registro por correo electrónico durante la vigencia del estado de alarma, lo que es ratificado por la Mesa el 24 de marzo (BPCCL 94); la Mesa delega en el Presidente la resolución de los asuntos urgentes durante la situación derivada de la crisis sanitaria, delegación que se ejercerá previa consulta a los miembros de la Mesa. Asimismo, se habilita la celebración de reuniones telemáticas de la Mesa y de la Junta de Portavoces en el mismo periodo.

La suspensión de la actividad parlamentaria del segundo periodo de sesiones se levanta mediante acuerdo de la Mesa de 17 de abril (BOCCL n. ${ }^{\circ}$ 961) con efectos de 24 de abril, fecha en que se celebraría sesión del Pleno de las Cortes para la comparecencia del Presidente de la Junta y la convalidación de un decreto-ley. El acuerdo especifica que durante la permanencia de la situación de crisis sanitaria y la vigencia del estado de alarma, la actividad parlamentaria debería desarrollarse reduciendo al máximo posible la presencia 
de los procuradores y del personal de la Cámara en la sede de las Cortes. Por Resolución de la Presidencia de 21 de abril (BOCCL 97) se establecen normas para la emisión del voto por procedimiento telemático durante la crisis sanitaria, considerando justificada la no asistencia de los procuradores a las sesiones plenarias y autorizando la participación en las votaciones en tal forma. Por acuerdo de la Mesa de 28 de abril se deja sin efecto el Plan de contingencia aprobado el 13 de marzo. El primer Pleno de control se celebraría el 12 de mayo. Las sesiones plenarias en dos jornadas se retoman el 9 de junio.

Durante el periodo de suspensión, la Diputación Permanente se reunió una sola vez, el 17 de marzo, para la comparecencia del Presidente de la Junta. Hubo aquí, como en otros Parlamentos, tal vez cierto apresuramiento en la habilitación de la Diputación Permanente para fines que habrían podido conseguirse por medios más ortodoxos, como la reunión del Pleno con una asistencia reducida, aunque pueda tenerse en cuenta en este caso para comprender la decisión adoptada la amplitud territorial de la CA, que se extiende a 9 provincias.

— en el Parlamento de las Islas Baleares, la Mesa, constituida como tal en la reunión de la Junta de Portavoces de 12 de marzo de 2020, acordó no celebrar la sesión convocada para el día 17 de marzo ni la prevista para el 23 al 27 de marzo, haciendo excepción del artículo 63.2 del Reglamento que prevé un mínimo Pleno semanal durante los periodos de sesiones, salvo acuerdo unánime en sentido contrario, oída la Junta de Portavoces; la suspensión de las comisiones parlamentarias del 16 al 27 de marzo; aprobar un Plan de contingencia y la regulación de la gestión económica de la Cámara; y otras medidas complementarias, como la habilitación del correo electrónico para la presentación de documentos en el Registro (BOPIB n. ${ }^{\circ} 36$ ). El 16 de marzo, la Mesa acordó diversas medidas, entre ellas que, para continuar con la labor parlamentaria imprescindible, se podría convocar la Diputación Permanente, cuyas condiciones de participación reducida se establecieron el 30 de marzo. Las sesiones se celebrarían presencialmente en formato reducido, asistiendo como mínimo tres miembros de la Mesa y un miembro por grupo parlamentario, habilitando la votación telemática por un procedimiento simplificado; por las circunstancias de limitación del tráfico marítimo y/o del alojamiento, un miembro del Grupo Mixto podría participar por videoconferencia. El 7 de abril, la Diputación Permanente convalidó tres decretos-leyes con voto personal y telemático (Diario de Sesiones num. 9), única sesión que habría podido evitarse, pues el 8 de abril la Mesa y la Junta de Portavoces, por unanimidad, acuerdan levantar la suspensión de las sesiones plenarias, así como la suspensión de plazos sobre preguntas con respuesta escrita y solicitudes de documentación, manteniéndola para el resto de iniciativas. Se dejan sin efecto las funciones de la Diputación Permanente previstas durante el estado de alarma, asumiendo el Pleno esas 
funciones con el mismo formato reducido. Se establece el contenido de las sesiones plenarias: preguntas orales y su distribución, convalidación de decretos-leyes y determinadas iniciativas legislativas que permitan la votación telemática, que se habilita con un procedimiento simplificado. La primera sesión plenaria se celebra el 21 de abril.

El 16 de abril, la Mesa acordó — además de la cesión de un remanente de 8 millones de euros al Gobierno de la Comunidad para el mantenimiento de los servicios esenciales durante la crisis sanitaria- (BOIPB 41) levantar la suspensión de la actividad de las comisiones permanentes (de las no permanentes se alzaría a partir del 15 de mayo por acuerdo del día 13, BOPIB 45, como también la limitación de la actividad de las permanentes a materias relacionadas con la pandemia ${ }^{19}$. Se autoriza la celebración de Mesas de las comisiones por videoconferencia o sistema técnico similar adecuado para garantizar su seguimiento. El 19 de junio, un acuerdo de la Mesa regula la actividad parlamentaria en un contexto de nueva normalidad (BOIPB 50).

Obsérvese cómo, sin perjuicio de incurrir en la apresurada habilitación de la DP que habría podido evitarse, la videoconferencia en las sesiones se reduce a los casos en que la doble insularidad impide la asistencia, problemática que sólo comparte la Comunidad de Canarias.

- en el Parlamento de Canarias, la Mesa acordó el 13 de marzo, la desconvocatoria de las comisiones previstas; el 16 de marzo (BOPC 92a), la suspensión de la actividad parlamentaria ordinaria durante el periodo de vigencia del estado de alarma y la restricción a la estrictamente necesaria para el cumplimiento y desarrollo de las medidas previstas en el Real Decreto de declaración de aquél. Las reuniones de Mesa y JP se celebrarían de forma no presencial salvo que fuera imprescindible la presencia; se suspende la tramitación de todos los asuntos parlamentarios y el cómputo de plazos, así como el registro de iniciativas, manteniéndose las relaciones con el Gobierno por correo electrónico y teléfono. Se habilita un correo electrónico para el registro de iniciativas y asuntos urgentes e inaplazables (aunque antes se suspende el registro de iniciativas).

El 27 de marzo, la Mesa acordó autorizar la celebración de reuniones de la Diputación Permanente a través de sistemas telemáticos y la delegación de voto de sus integrantes, a consecuencia de la pandemia de coronavirus (BOPC 98, de

19 Las sesiones tendrían una duración máxima de 3 horas, con carácter preferentemente presencial, para lo que se utilizaría el salón de plenos, con la posible participación por videoconferencia de los diputados residentes en las islas de Menorca, Ibiza o Formentera (ya prevista en el art. 49 del Reglamento de 19 de marzo de 2019), dada la limitación y reducción del tránsito aéreo y marítimo. El Presidente o el Vicepresidente de la Comisión deberían asistir personalmente y, si residiera en estas islas y no pudiera hacerlo, el Presidente de la Cámara presidiría, sin derecho a voto, sin perjuicio de que aquellos pudieran participar por videoconferencia en las mismas condiciones que los demás miembros de la comisión. 
misma fecha). Asimismo se establece excepcionalmente la posibilidad de delegación de voto por los miembros de la DP en el presidente o portavoz de su grupo parlamentario. Al inicio de la sesión, la DP habría de pronunciarse expresamente sobre la asunción de la competencia para tratar los asuntos incluidos en el orden del día. Si convalidare un decreto-ley, le correspondería igualmente pronunciarse sobre su tramitación como proyecto de ley.

El 2 de abril, la Mesa, de acuerdo con la JP, modificó la Resolución para admitir de forma excepcional mientras persistiera la crisis sanitaria la asistencia de suplentes o de otros sustitutos no miembros de la DP en atención a la materia a tratar (BOPC 106). Se publica el calendario de actividades de la DP, con comparecencias de miembros del Gobierno, y se exceptúa el envío de documentación aneja a las convocatorias. El 7 de abril se publica un decreto ley, respecto del que la Mesa acuerda, visto el informe del Servicio Jurídico sobre la viabilidad jurídica de celebrar una sesión de la DP para su convalidación o derogación, supeditar la fijación de la sesión a la comunicación de la aprobación del decreto-ley aprobado. El 16 de abril, se incluyen en el calendario de la DP sesiones para la convalidación de decretos-leyes y se establecen los criterios para la presentación semanal de iniciativas para su inclusión en sus sesiones, fijando el cupo de preguntas orales en Pleno para cada grupo, así como de preguntas dirigidas a la presidencia del Gobierno, y un cupo semanal de comparecencias (BOPC 123). Se exceptúa de la suspensión la solicitud de datos, informes y documentos relacionados con la gestión de la situación de crisis sanitaria, fijando un cupo por grupos (BOPC n. ${ }^{\circ}$ 124). La DP se reúne los días $8,14,17,21,24,28$ y 29 de abril y 5 de mayo, para la convalidación de decretos-leyes y la celebración de comparecencias. El Pleno, que había reanudado sus sesiones el día 15 con 25 diputados presentes, aprueba el 20 de mayo una reforma del Reglamento que permite la participación mixta presencial y mediante videoconferencia en Pleno y comisión (arts. 19, 69, 70, 82.2 y 92, BOPC 159). El 27 de mayo se reanudan las sesiones de comisión con asistencia reducida y videoconferencia ${ }^{20}$. Un acuerdo de la Mesa de 8 de junio (BOPC 189) regula el desarrollo de las sesiones de Pleno y comisión con voto telemático. El 11 de junio se acuerda excepcionar hasta el 30 de junio a los diputados que residen en islas no capitalinas de la obligación de participar y votar presencialmente en las sesiones de las comisiones, cuando exista imposibilidad de transporte (BOPC 191) ${ }^{21}$.

20 Un acuerdo de la Mesa de 8 de junio (BOPC 187/2) deja sin efecto la suspensión de la indemnización a percibir por los parlamentarios que asisten a sesiones plenarias por medios telemáticos desde una sede institucional.

21 Se acuerda también la entrega a organizaciones no gubernamentales, previa la correspondiente modificación de crédito, del importe de las indemnizaciones que se habrían devengado en situación de normalidad y otros gastos de celebración de sesiones. 
En resumen: la decisión de reemplazar el Pleno y las comisiones por la DP ha ido acompañada de acuerdos sobre sustitución de miembros por no miembros, extensión o ampliación de la delegación de voto y otros, además de la celebración telemática de las sesiones. Es cierto que Canarias es una Comunidad insular, con problemas de comunicación entre las islas agravados por la crisis sanitaria. No obstante, podrían haberse arbitrado otros recursos para la reunión del Pleno, si fuera necesario (pensemos en que apenas se reúne la DP durante el primer periodo de suspensión), y posteriormente de las comisiones para comparecencias. Si para el órgano que sustituye al Pleno no se duda en admitir la reunión telemática, más fácil sería para las comisiones, sin acudir al recurso extremo de la Diputación, que estuvo reuniéndose hasta fecha tan avanzada como el 5 de mayo, un día antes de autorizarse la cuarta prórroga del estado de alarma. De hecho, el 7 de mayo la Mesa acuerda (BOPC 138, misma fecha) la recuperación progresiva de la celebración de sesiones plenarias — dejando sin efecto la habilitación de la DP_ con presencia limitada y delegación de voto conforme al artículo 92.6 del Reglamento (temporal y excepcional por causa de fuerza mayor), así como la celebración de sesiones de comisiones con presencia física de la totalidad de sus miembros, salvo la posibilidad de que la Mesa autorizara la reunión telemática de la Comisión de Reglamento para estudiar una propuesta de reforma sobre participación y votación telemática.

\section{CONGRESO DE LOS DIPUTADOS...Y SENADO}

Se ha dejado para el final el examen de la actividad de las Cámaras que integran las Cortes Generales para no desviarnos del objeto de este trabajo. En efecto, si hay una Cámara que debe ser protagonista durante el estado de alarma es el Congreso de los Diputados, el cual —según dispone el artículo 116 CE— debe ser informado de su declaración «reunido inmediatamente al efecto», autoriza la prórroga (o más de una, como en este caso en que fueron 6) y no puede ser disuelto durante la vigencia de aquel, asumiendo las competencias la Diputación Permanente en caso de disolución o expiración de mandato. De otra parte, afectan a ambas Cámaras los apartados 5 y 6 de dicho artículo en cuanto a la convocatoria automática si no estuvieren en período de sesiones y a la no modificación del principio de responsabilidad del Gobierno y sus agentes reconocidos en la Constitución y en las leyes; no en vano el artículo 66.2 CE atribuye a las Cortes Generales el control de la acción del Gobierno.

Un trabajo monográfico podría dedicarse a esas cuestiones de fondo y comprobar si se ha ejercido adecuadamente la función de control durante el estado de alarma. Aquí nos quedamos en el propósito más modesto de ver la forma en que se ha mantenido el funcionamiento de ambas Cámaras, en particular de la primera por las razones señaladas. No siendo siempre públicos los acuerdos de sus órganos de gobierno, la tarea se limitará muchas veces a la exposición de hechos, incluso conocidos por los comunicados de prensa o a través de los medios de comunicación. 


\section{Congreso}

En el Congreso, ante la negativa de un grupo parlamentario a asistir por contar con un miembro contagiado, se suspende la sesión plenaria prevista para la semana del 10 de marzo, así como una sesión de comisión. El 12 de marzo, la Presidenta anuncia —y recoge una nota de prensa—, que la actividad se suspende durante dos semanas, según acuerdo de la Junta de Portavoces. Se mantienen las reuniones, en su mayor parte telemáticas, de la Mesa y la Junta de Portavoces, así como el registro telemático de las iniciativas. La Secretaría General establece un Plan de Actuación frente a la situación epidemiológica.

El 18 de marzo comparece el Presidente del Gobierno ante el Pleno, con la asistencia reducida a una veintena de diputados, para presentar la comunicación del Gobierno sobre la declaración del estado de alarma, de conformidad con el artículo 165 RC, según el cual en los supuestos previstos en los tres artículos anteriores (sobre las competencias del Congreso en los estados de emergencia constitucional $^{22}$ ), «el asunto será sometido inmediatamente al Pleno del Congreso, convocado al efecto si no estuviere reunido, incluso en el periodo entre sesiones».

El 19 de marzo, la Mesa adopta un acuerdo por el que, teniendo en cuenta la declaración del estado de alarma por RD 463/2020, y atendiendo a las especiales circunstancias concurrentes, se permite que, mientras dure dicho estado de alarma y previa petición del grupo parlamentario correspondiente, todos los diputados que lo deseen puedan emitir su voto por el procedimiento telemático en las sesiones plenarias que se celebren durante este. El voto telemático está previsto por el artículo 82.2 del Reglamento desde su reforma de 21 de julio de 2011 para casos de embarazo, maternidad, paternidad o enfermedad grave en que, por impedir el desempeño de la función parlamentaria y atendidas las especiales circunstancias se considere suficientemente justificado, previa autorización de la $\mathrm{Mesa}^{23}$. El artículo 79.3 RC establece que se computarán como presentes en la votación los miembros de la Cámara que, pese a estar ausentes, hayan sido expresamente autorizados por la Mesa para participar en la misma.

Una nota de la Secretaría General del Congreso de 25 de marzo sobre la posibilidad de realizar sesiones del Pleno, las comisiones u otros órganos de la Cámara

22 En cuanto a la declaración del estado de alarma, art. 162.1 RC: «Cuando el Gobierno declarase el estado de alarma, remitirá inmediatamente al Presidente del Congreso una comunicación a la que acompañará el Decreto acordado en Consejo de Ministros. De la comunicación se dará traslado a la Comisión competente, que podrá recabar la información y documentación que estime procedente».

23 El desarrollo del procedimiento de votación telemática, con confirmación telefónica, para las sesiones plenarias en aquellas votaciones no susceptibles de fragmentación o modificación, se regula por la Resolución de la Mesa del Congreso de 21 de mayo de 2012 y se utiliza con normalidad desde entonces. El procedimiento se ha flexibilizado durante la crisis por dificultades tecnológicas, dada la elevación a más de 300 del número de diputados que han de ejercer su voto en un tiempo limitado (así para las prórrogas de estado de alarma, tras la incorporación de propuestas); los diputados votan en la intranet, sin confirmación telefónica o vía mail. 
mediante el sistema de videoconferencia, que responde a las solicitudes de varios grupos parlamentarios pidiendo que se facilite la intervención mediante videoconferencia, examina por separado las cuestiones que se plantean en relación con el Pleno, las comisiones y otros órganos, como la Mesa y la Junta de Portavoces. En cuanto al Pleno, se pronuncia en sentido contrario, sobre la base del artículo 70.2 $\mathrm{RC}$, que establece que los discursos se pronunciarán personalmente y de viva voz, y que el orador podrá hacer uso de la palabra desde la tribuna y desde el escaño, sin previsión de intervenir en ausencia o fuera del Salón de Plenos, dada la inmediatez como esencia misma del debate. La exigencia de presencia a efectos de quorum fue matizada por la reforma de 21 de julio de 2011 (arts. 82 y 79.3, ya citados), que computa como presentes en la votación los miembros ausentes expresamente autorizados por la Mesa para participar en ella, esto es, los que emiten su voto de forma telemática. No se modificó el artículo 70, «puesto que, a diferencia del carácter personal e indelegable del voto en el caso de los debates sí cabe la sustitución de los diputados por otro de su mismo grupo parlamentario» (art. 70.4). El informe se apoya asimismo en la jurisprudencia del TC, SSTC 19/2019 y 45/2019, en la primera de las cuales (FJ 4) se señala, entre otras cosas, que «la presencia de los parlamentarios en las Cámaras y en sus órganos internos es un requisito necesario para que puedan deliberar y adoptar acuerdos», citando el artículo $79 \mathrm{CE}$; «en los procedimientos parlamentarios la interacción de los presentes es un elemento esencial para que la Cámara pueda formar su voluntad», mediante el debate y discusión, y para ello «es esencial que los parlamentarios asistan a las sesiones de la Cámara»; «sólo de este modo se garantiza que puedan ser tomados en consideración aspectos que únicamente pueden percibirse a través del contacto personal», sin otra excepción «que la que pueda venir establecida en los reglamentos parlamentarios respecto a la posibilidad de votar en ausencia cuando concurran circunstancias excepcionales o de fuerza mayor», con las debidas garantías de que se expresa la voluntad del parlamentario ausente y no de un tercero. Todo ello, aparte la función simbólica de materializar la representación del pueblo (FJ 5).

La nota concluye rechazando la posibilidad de intervenir por videoconferencia en las sesiones plenarias, salvo que se modifique el Reglamento que la contemple, sólo por motivos excepcionales, citando el ejemplo de la modificación de la Ley del Gobierno a que se alude en nota 4 . Se recuerda que ya se ha tomado alguna medida para las circunstancias excepcionales como el Acuerdo de la Mesa de 19 de marzo de 2020, de extensión a todos los diputados de la autorización para emitir voto telemático. Ello permite celebrar las sesiones con puntos a votar con un número mínimo de diputados presentes, como ocurrió el 18 de marzo, en cumplimiento de las recomendaciones de las autoridades sanitarias.

La nota afirma que, desde el punto de vista técnico, el Congreso no cuenta, por el momento, con los medios necesarios para poder celebrar una sesión plenaria mediante videoconferencia, ni siquiera en la que — no ya todos los miembros — tan sólo algunos portavoces hicieran uso de estos sistemas y hubiese que atender a todos a la vez. Las pantallas del hemiciclo que reflejan el resultado de las votaciones permiten la proyección de una única señal que se distribuye a todas las cadenas de televisión, y por eso no podría sustituirse por la emisión de varias imágenes procedentes cada una de una señal diferente. 
En cuanto a las comisiones, la nota recuerda que les son de aplicación las normas citadas sobre los debates, así como la doctrina del TC, siendo en cambio posiblemente menores las dificultades técnicas, tanto por el número más reducido de sus miembros como por la posibilidad de celebrar sus sesiones en distintas salas, algunas con medios técnicos más avanzados, donde se han celebrado ya desde 2006 algunas comparecencias por videoconferencia de autoridades como los Comisarios de la Unión Europea y expertos que se encontraban fuera de España, con los diputados presentes en la sala.

Finalmente, en cuanto a las reuniones de la Mesa y la Junta de Portavoces, el criterio es diferente, dado su carácter de órganos rectores de la organización y funcionamiento de la Cámara, que se reúnen siempre a puerta cerrada, no siendo públicos sus debates ni recogiéndose en el Diario de sesiones, sino en unas actas fundamentalmente de acuerdos, aunque hagan sucinta referencia a las posturas defendidas. Se ha entendido, por tanto, que cabe la participación en ausencia de la sala en que se celebren, por razones excepcionales y existiendo una sede física de la reunión dentro del Congreso que permita ejercer la presidencia y dirección de la reunión, así como su seguimiento por quienes han de redactar el acta.

El día 25 se celebra sesión plenaria para la convalidación de cinco decretos-leyes y la autorización de la prórroga del estado de alarma hasta el día 12 de abril; se rechazan las propuestas presentadas por seis grupos parlamentarios, se incluye en el RD de declaración (463/2020) a propuesta del Grupo Vasco una disposición adicional sexta en virtud de la cual, de conformidad con lo establecido en el apartado uno del artículo octavo de la Ley Orgánica 4/1981, de los estados de alarma, excepción y sitio, el Gobierno remitiría semanalmente al Congreso de los Diputados información documental estructurada de la ejecución de las distintas medidas adoptadas y valoración de su eficacia para contener el COVID-19 y mitigar su impacto sanitario, económico y social, modificación introducida por RD 476/2020 24 . La sesión tiene lugar con asistencia reducida a 43 miembros (una décima parte de los diputados, según acuerdo alcanzado entre los portavoces, así como los miembros de la Mesa) y habilitación para todos los diputados del voto telemático, emitiéndose 306 votos por esta vía (más 43 presenciales, total 349).

Se inician las comparecencias del Ministro de Sanidad — autoridad delegada con competencia propia y residual - ante la Comisión correspondiente el 2 de abril, continuando el seguimiento las semanas posteriores.

El 7 de abril, la Mesa del Congreso, además de aprobar destinar tres millones de euros de sus remanentes a la financiación de los gastos ocasionados por el Covid19, acuerda el levantamiento de la suspensión del cómputo de plazos en la tramitación de iniciativas, hito que marca la reactivación de la labor parlamentaria de la

24 De conformidad con el art. 6 LO 4/1981, de los estados de alarma, excepción y sitio, «2. En el decreto se determinará el ámbito territorial, la duración y los efectos del estado de alarma, que no podrá exceder de quince días. Sólo se podrá prorrogar con autorización expresa del Congreso de los Diputados, que en este caso podrá establecer el alcance y las condiciones vigentes durante la prórroga». 
Cámara, por más que limitada. La Junta de Portavoces acuerda la reanudación la semana siguiente de las sesiones de control al Gobierno.

El 9 de abril, el Pleno del Congreso autoriza la segunda prórroga del estado de alarma hasta el 25 de abril, con 306 votos emitidos de forma telemática, y convalida tres decretos leyes con 304 votos por esta vía. La primera sesión ordinaria de control al Gobierno se celebra el día 15 de abril, en formato reducido (tercera sesión plenaria desde la declaración del estado de alarma), con quince preguntas y tres interpelaciones urgentes en el orden del día, además de aprobarse por asentimiento — se utiliza esta forma de aprobación por no precisar la comprobación del quorum de votación ${ }^{25}$ - la creación de una comisión de investigación relativa al accidente aéreo del vuelo JK5022 de Spanair, sobre el que una comisión similar no había concluido sus trabajos en la XII legislatura. El mismo día tiene lugar una reunión de comisión para comparecencia de Ministro.

La semana del 20 de abril se celebran tres sesiones de comisiones en orden a la comparecencia de ministros para informar sobre la gestión en relación con el coronavirus. El 22 de abril, el Pleno se reúne para la comparecencia del Presidente del Gobierno para informar de Consejos europeos, autorizar la tercera prórroga del estado de alarma con 295 votos telemáticos y 50 presentes (se rechazan las propuestas de 5 grupos parlamentarios) y convalidar un decreto-ley, emitiéndose 300 votos electrónicos y 50 presentes, así como para celebrar sesión de control al Gobierno, con 15 preguntas orales y tres interpelaciones urgentes. Se celebra asimismo sesión de control el 29 de abril, con preguntas e interpelaciones urgentes, así como la convalidación de decretos-leyes (45 votos presenciales y 305 telemáticos). El 6 de mayo se autoriza la cuarta prórroga del estado de alarma hasta el 23 de mayo incluido, emitiéndose 46 votos presenciales y 304 telemáticos, previo rechazo de las propuestas presentadas por cuatro grupos parlamentarios y la aprobación de las del Grupo Vasco. Las sesiones plenarias semanales continúan a partir del 13 de mayo, con control y decretos-leyes; junto a este orden del día habitual, el 20 de mayo se autoriza la quinta prórroga, hasta el 6 de junio incluido, y se convalida un decreto-ley, emitiéndose 46 votos presenciales y 304 telemáticos respecto de la primera y 46-301 para lo segundo. La sexta prórroga, hasta el 20 de junio inclusive, se aprobaría el 3 de junio con 92 votos presenciales y 258 telemáticos, incrementándose la asistencia en esta fase de la desescalada parlamentaria a más del $25 \%$ de los diputados; en esta fecha se incluyen también en el orden del día por primera vez los debates de totalidad de un convenio internacional y un proyecto de ley, así como la toma en consideración de una proposición de ley, en un paso más hacia la normalidad. También por primera vez, superadas las dificultades de alojamiento, la sesión se prolonga dos días, con el horario habitual y la incorporación de mociones consecuencia de interpelación a partir del 16 de junio,

25 Ver en el Diario de Sesiones incidente sobre la forma de votación de Vicepresidente en la Comisión de Sanidad el 17 de abril de 2020. 
en la que más de un tercio de los votos emitidos son presenciales, 112; se recuperan las sesiones de tres días el 23 de junio, concluido el estado de alarma. No obstante, por acuerdo de la Mesa de 16 de junio, se prorroga el acuerdo de extensión del voto telemático hasta la finalización de la crisis sanitaria, según lo previsto en el artículo 2.3 del RD-ley 21/2020.

De lo expuesto podemos concluir que el Congreso esquivó las tentaciones fáciles a las que sucumbieron otros parlamentos y mantuvo la presencialidad de las sesiones plenarias y de comisión, con un formato reducido y con la extensión por la Mesa — mal menor, en mi opinión- de las previsiones reglamentarias sobre supuestos para autorizar el voto telemático.

Tras una suspensión durante las primeras dos semanas, y dada la necesidad de autorizar las prórrogas del estado de alarma, la actividad del Pleno se reinicia, para este punto y para la convalidación de los numerosos decretos leyes dictados, así como para comparecencias en Pleno y en comisión. Las sesiones ordinarias de control - preguntas e interpelaciones, sin inclusión de las mociones consecuencia de éstas ${ }^{26}$ — se retoman con carácter semanal a partir del 15 de abril, un mes después de la suspensión, periodo de duración no reprochable habida cuenta de la escalada de la pandemia. Los enfrentamientos políticos — más o menos constructivos - se trasladan también al Congreso con la creación por la Mesa el 28 de abril de la Comisión no permanente para la reconstrucción social y económica, solicitada por los Grupos Socialista y de Unidas Podemos-ECP-GEC, que se constituye el 7 de mayo ${ }^{27}$ y comienza a trabajar a destajo. De otra parte, la actividad ordinaria de registro de iniciativas se ha mantenido inalterada durante todo el estado de alarma, siendo elevado, por ejemplo, el número de preguntas al Gobierno para respuesta escrita.

\section{Senado}

Dado que las competencias constitucionales sobre los estados regulados en el artículo 116 CE corresponden al Congreso, la presencia de la Alta Cámara ha

26 No se incluyen en el orden del día de la sesión de control las mociones consecuencia de interpelaciones formuladas en la sesión anterior por cuanto la eventual introducción de enmiendas aceptadas en el curso del debate impide la votación telemática previa, en los términos de la Resolución que regula esta.

27 La Comisión está compuesta por 46 miembros, adopta sus decisiones por voto ponderado (de forma que no sería necesaria una composición tan amplia, habida cuenta de que las Comisiones permanentes están integradas en la XIV legislatura por 37 miembros y que las comisiones especiales suelen ser más reducidas), que se extiende incluso a la totalidad de las formaciones que componen los Grupos Plural y Mixto —algo absolutamente insólito-, y con un plazo inicial de dos meses prorrogables para sus trabajos. El dictamen que contenía sus conclusiones en cuatro áreas (sanidad y salud pública, reactivación económica, políticas sociales y sistema de cuidados, y Unión Europea) se debatió en el Pleno de la Cámara de 21 de julio y se votó el día 22, resultando rechazado el tercer bloque. Una irregularidad (un parlamentario solicitó votar telemáticamente y lo hizo presencialmente sin previo acuerdo de la Mesa de modificación), dio lugar a la Resolución de la Presidencia de 22 de julio (BOCG 127), que rectificaba los resultados de las votaciones de la sesión; el empate provocó la repetición de la votación sobre el segundo bloque el 29 de julio, siendo aprobado. El texto puede verse en BOCG 130. 
quedado un tanto difuminada durante el primer mes de alarma, pese a que la coordinación con las Comunidades Autónomas era esencial en la lucha contra la enfermedad, lo que llevaba a pensar en la conveniencia de la convocatoria de la Comisión General de las Comunidades Autónomas.

El día 12 de marzo, la Mesa acordó extender a todos los senadores el voto telemático regulado por el artículo 93.2 RS (el apartado 3 establece su cómputo para el quórum) en relación con la autorización de un convenio internacional incluido en el orden del día de la siguiente sesión plenaria y suspender los plazos de tramitación, desconvocar las sesiones de las comisiones y sus órganos para las dos siguientes semanas. El 17 de marzo, el Pleno adopta el acuerdo sobre el convenio internacional con 259 votos telemáticos y 5 presenciales a mano alzada, de los cuales 4 de miembros de la Mesa (el senador restante había tenido problemas con la emisión de su voto telemático y optó por la presencia). Ese mismo día, la Mesa del Senado adoptó el acuerdo de no convocar sesiones de Pleno ni de comisiones durante la vigencia del estado de alarma, sin perjuicio de que pudieran convocarse para la tramitación de asuntos de urgencia o para dar cumplimiento a las obligaciones constitucionalmente atribuidas al Senado cuando estas resultaran inaplazables. Se suspendieron el registro presencial y los plazos administrativos (que se reanudarían el 1 de junio, BOCG Senado 51), habiéndose suspendido los reglamentarios el día 12.

Planteada la adecuación a derecho de este acuerdo por el Grupo Popular, en concreto con el artículo 116.5 CE y con el artículo 1.4 de la LO 4/1981, de los estados de alarma, excepción y sitio, una nota de la Secretaría General de 9 de abril, que analiza los requerimientos de no interrupción del funcionamiento de las Cámaras contenido en el primero de los preceptos, a la que el segundo añade el calificativo de normal, recuerda que no es el estado de alarma el que ha alterado el normal funcionamiento del Senado, sino la pandemia causa de la declaración, que ha llevado a adoptar una serie de medidas por los órganos competentes de la Cámara que se enumeran: el 12 de marzo, la extensión del voto telemático más allá de las estrictas previsiones contenidas en el artículo 93.2 RS, a todos los senadores; el día 17 de marzo, el acuerdo de no convocatoria referido más arriba y autorizar la presentación y registro de iniciativas por medios electrónicos, limitando el horario de registro; celebrar las reuniones de la Mesa y de la Junta de Portavoces por videoconferencia, aunque con presencia física de alguno de sus integrantes en el Palacio del Senado; establecer servicios esenciales y otras medidas para el personal. La nota destaca la constitucionalidad y legalidad de estas medidas, situando la mayor dificultad para un funcionamiento del Senado y de sus órganos más cercano a la normalidad en la imposibilidad jurídica y técnica para llevar a cabo sesiones plenarias y de comisiones por videoconferencia, imposibilidad objeto de sendas notas anteriores, examinadas por la Junta de Portavoces y la Mesa en reuniones de 17 de marzo.

Con el acuerdo de suspensión en cuestión no se cierra la posibilidad de celebrar sesiones en caso de urgencia o cumplimiento de obligaciones constitucionales inaplazables. En este sentido, la Mesa acordó el 31 de marzo autorizar la convocatoria de la CGCA en el plazo más breve posible para debatir la situación generada por el 
estado de alarma en las diferentes Comunidades Autónomas, como excepción. La nota concluye que el acuerdo cuestionado puede considerarse jurídicamente correcto, y temporalmente adecuado a las circunstancias en las que se dictó, sin que ello obste a que las limitaciones pudieran modularse si las circunstancias que lo fundamentaron variasen para adaptarse a la nueva situación. En cuanto a las consecuencias, planteadas en el escrito del Grupo Popular, que se podrían derivar de este acuerdo en el orden jurisdiccional, la nota, sin perjuicio de no apreciar infracción constitucional, señala la vía del recurso de amparo, descartando la vía penal por no haber margen para la comisión de un delito.

Como puede verse, el acuerdo inicial de la Mesa de suspensión de la actividad estaba previsto para un estado de alarma quizá no tan prolongado, y fue modificado a medida que aquél se prorrogaba. De hecho, el Pleno reanudó sus sesiones el 21 de abril - es decir, transcurrido algo más de un mes de la declaración- con el control al Gobierno (quince preguntas y tres interpelaciones), según acuerdo de la Mesa de 14 de abril ${ }^{28}$, estando la asistencia reducida a un máximo del diez por ciento de los representantes de cada grupo parlamentario. En esta fecha se levanta la suspensión de plazos reglamentarios de iniciativas en tramitación con efectos de 30 de abril. Continúan las sesiones de control a partir del 5 de mayo y las de comisiones se reinician a partir del 7 de mayo, esa semana autorizadas el día 5 todavía con carácter excepcional, levantándose su suspensión por la Mesa el 12 de mayo (con asistencia reducida en función del tamaño del grupo).

La sesión de la CGCA — autorizada por la Mesa gracias al voto favorable del PNV - tuvo lugar el día 30 de abril con la presencia de la Ministra de Política Territorial y Función Pública por parte del Gobierno, y de sólo cuatro Presidentes de Comunidad Autónoma (Cantabria, Murcia, Madrid y Castilla y León) y el de la Ciudad Autónoma de Ceuta, siendo el nivel de representación de menor rango en otras CCAA, todo lo cual rebajaba la relevancia de la reunión.

Se aplaza — no se celebraría hasta la última semana de mayo- la sesión ordinaria de control de la Administradora única de RTVE en la Comisión Mixta competente prevista para la semana del 27 de abril y reclamada por los grupos de oposición, sin recurrir siquiera a la comparecencia telemática atendido su carácter de persona de riesgo, que debería ser autorizada por las Mesas de ambas Cámaras por tratarse de una comisión mixta.

En previsión de la reanudación de la actividad ordinaria con presencia reducida, una Norma Supletoria de la Presidencia de 8 de junio establece que, mientras las medidas de distanciamiento físico impidan la presencia de la totalidad de los senadores en las sesiones plenarias, todos ellos emitirán su voto por procedimiento telemático en cualquier tipo de votación, garantizando la identidad del

28 La Mesa autoriza la transferencia de tres millones de euros al Tesoro Público, con cargo al Fondo de Remanentes Presupuestarios, para contribuir a los gastos ocasionados por la crisis sanitaria. 
votante y el sentido de su voto, mientras el mantenimiento de las medidas de distanciamiento físico impida la presencia de la totalidad de los senadores en las sesiones plenarias (BOCG 54). La norma incluye la posibilidad novedosa, y un tanto inquietante por la ruptura del principio de inmediatez (aunque se pretenda con ello respetar la finalidad de la deliberación), de que la sesión finalice antes de hacer público el resultado de alguna votación, que se comunicará a los senadores y se publicará en la página web a la mayor brevedad, dando cuenta del mismo al inicio de la siguiente sesión plenaria. El 17 de junio — sesión en la que todos los votos se emiten telemáticamente - se rechaza la creación de una Comisión Especial para la recuperación social y económica de España, propuesta por el Grupo Popular (alegando la duplicidad con el Congreso); el resultado oficial se proclamaría en la sesión plenaria de 30 de junio.

Una presencia más activa del Senado y su reflejo mediático — siempre difícil de conseguir — habría redundado en favor de la Cámara. ¿Alguien ha recordado que el Senado es la sede de la Conferencia de Presidentes — según su Reglamento interno de 2009-, cuya utilidad como instrumento de cooperación entre el Gobierno y las CCAA se ha descubierto en estos días? ${ }^{29}$

\section{CONCLUSIONES}

A lo largo de este trabajo hemos podido examinar la reacción de los distintos Parlamentos españoles frente a las dificultades para su funcionamiento planteadas por la pandemia de Covid-19 y la consiguiente declaración del estado de alarma.

De una parte, se encuentran los dos supuestos de Parlamentos disueltos, en Galicia y País Vasco, que han recurrido a una ampliación de las funciones tradicionales y reglamentarias de la Diputación Permanente, cierto que con una justificación evidente: en disolución, se trata del único órgano vivo, y el período provisional en que está llamado a ejercer sus funciones se ha alargado al suspenderse sine die —cuestión inédita y sin apoyo legal- las elecciones de nuevas Cámaras previstas para el 5 de abril, que finalmente se celebrarían el 12 de julio.

De otra parte, prácticamente todos los Parlamentos suspendieron su actividad durante el primer mes de escalada de la pandemia que coincide con la declaración del estado de alarma y la primera prórroga, salvo algunas reuniones inaplazables. En este primer periodo, los órganos rectores de algunos de aquellos se apresuraron a suspender el periodo de sesiones y/o activar la Diputación Permanente, sin apoyo reglamentario real. Su reunión a veces en formato reducido y voto ponderado o a distancia hace aún menos justificado acudir a ese órgano, lo que se pone de manifiesto en particular cuando harta la reanudación de la actividad

29 Frente a seis reuniones desde su creación en 2004 hasta 2017, se celebraron a catorce reuniones telemáticas, de periodicidad semanal, durante el estado de alarma desde La Moncloa. 
de los órganos ordinarios, con mayores o menores limitaciones, aquélla se ha reunido una sola vez.

Algunas Cámaras (Congreso, Senado, Cataluña, Cantabria) desde un primer momento se inclinan por mantener la presencialidad de las sesiones, proclamada por el Tribunal Constitucional en sentencias 19 y 45/2019, acudiendo en su caso al formato reducido de asistencia y su complemento de ampliación de los supuestos reglamentarios de autorización del voto telemático o por delegación, bien es verdad que por acuerdo de la Mesa por analogía y no mediante reforma reglamentaria. Este parece haber sido el mal menor, o el camino menos irregular desde el punto de vista jurídico, más correcto en el caso de que los supuestos estuvieran establecidos por una Resolución de la Presidencia, de fácil modificación.

A veces con el mismo tenor reglamentario que los anteriores tomado del modelo del Reglamento del Congreso (y en ocasiones con apoyo en informes jurídicos solicitados más bien para justificar decisiones ya adoptadas), otros Parlamentos han recurrido a la interpretación contraria, admitiendo la asistencia e incluso votación por videoconferencia, en una quiebra del principio de presencialidad e inmediatez peligrosa por las razones más arriba expuestas. En general, podemos afirmar que no plantean problemas las reuniones telemáticas de los órganos de gobierno de las Cámaras (Mesas y Juntas de Portavoces), que organizan ${ }^{30}$ pero no ejercen las funciones constitucionales o estatutarias de aquellas, a diferencia de sus órganos de trabajo: Pleno, comisiones y Diputación Permanente.

Debe tenerse en cuenta asimismo que, dado que durante los primeros momentos la actividad ha sido limitada (comparecencias sobre la pandemia, sin votaciones; convalidación de decretos-leyes por el Congreso, numerosos durante el estado de alarma; en un segundo momento de reanudación de la actividad, sesiones de control con preguntas y en su caso interpelaciones), tampoco este volumen ha requerido de excesivos desplazamientos, sobre todo cuando la sesión se celebraba en formato reducido. Y si en dos Parlamentos se han aprobado hasta leyes de presupuestos en curso de tramitación, razón de más para extremar el respeto a los procedimientos establecidos, acudiendo si fuera necesario a la reforma del Reglamento por vía de urgencia. El recurso más adelante a una Comisión de seguimiento o estudio - que no ejerce funciones ordinarias de control — ha sido también una opción contemplada para facilitar la presencialidad, alternativa siempre preferible a las reuniones informativas telemáticas de portavoces con miembros del Ejecutivo, que pueden llamar a confusión con las sesiones parlamentarias debidamente convocadas y celebradas.

Junto con los informes jurídicos, a veces la imposibilidad técnica ha salvado de las soluciones más extremas (Plenos o comisiones con asistencia e intervención telemática). Esperemos que las reformas reglamentarias que se anuncian no vayan

30 Es criticable que en algún caso se optara por la suspensión del registro de iniciativas en un primer momento, sin habilitar aunque fuera un correo electrónico para su envío telemático. 
en esa dirección ${ }^{31}$. Las Cortes de Cádiz tuvieron que sortear una guerra y un estado de sitio para reunirse, y la Constitución de 1812 ya previó la solución a sus problemas. Distintos Presidentes de Cámaras han recordado el carácter fundamental de la presencia del Parlamento en tiempos de crisis, con metáforas que lo comparan con el capitán que no abandona el barco (N. Pelosi, Congreso de EEUU) o hasta con los propios médicos que dan un paso adelante, no atrás ( $R$. Fico, Cámara italiana) $)^{32}$.

Cruz Villalón ${ }^{33}$ se pronunciaba contra una situación en la desescalada a medio camino entre el estado de alarma y la normalidad sin adjetivos, sin base constitucional precisa. Aquí también rechazamos los supuestos que se salen de la normalidad en el funcionamiento parlamentario — no intentando siquiera adaptarlo forzándolo lo menos posible — sin base reglamentaria precisa.

Una última preocupación es la que afecta al aumento del protagonismo de los grupos y sus portavoces en esta situación de crisis frente a los parlamentarios individuales — cuya participación no se echa en falta—, apareciendo aquellos como intermediarios, por ejemplo, en la solicitud de voto telemático. El ya de por sí mermado papel del representante no debería haber descendido otro escalón una vez que la excepcionalidad desaparezca, sino que habría de recuperar al menos la visibilidad anterior.

PS. El fin del estado de alarma obviamente no determinó el de la crisis sanitaria, siendo de temer que los rebrotes y oleadas de la pandemia afecten de nuevo al funcionamiento de nuestros parlamentos: el primero en suspender su actividad por contagios ba sido el balear, la segunda semana de septiembre de 2020. Esperemos que la experiencia adquirida contribuya a afrontar mejor las situaciones que puedan plantearse.

$$
* * *
$$

\section{TITLE: The ductility of Parliamentary Law in times of crisis}

ABSTRACT: The Covid-19 pandemic has caused serious interference in the functioning of parliaments, which led to different solutions in Spanish autonomous parliaments, Congress and Senate. This paper analyzes the decisions adopted by governing bodies to address the situation generated by the health crisis, where the presence of the institution was essential but neither regulatory provisions nor adequate technological tools were available. In opposition to some imaginative solutions, in which principles such as immediacy or attendance to sessions have been challenged, it is argued that the ductility of parliamentary law has limits if we want to stay within the bounds of the rule of law.

31 Proposiciones de reforma del Reglamento del Congreso para permitir la celebración de sesiones de forma telemática han sido presentadas por los Grupos Vox, UP-ECP-EM y Plural a instancia de JuntsxperCat - la última, rechazada por el Pleno el 17 de junio- (en el Senado, proposición de reforma de ER-EHBildu en el mismo sentido). Una proposición de ER que plantea la posibilidad de retirar a los diputados las indemnizaciones por ejercicio de la función parlamentaria en situaciones excepcionales que limiten o impidan el ejercicio del cargo, ha sido retirada (BOCG 82-2, 18 septiembre 2020).

32 Pueden verse estas y otras declaraciones en J. MurPHy, cit, p. 15.

33 «La Constitución bajo el estado de alarma», El País 17.04.2020. 
RESUMEN: La pandemia por Covid-19 ha provocado graves interferencias en el funcionamiento de los Parlamentos, que condujeron en nuestro país a soluciones diversas en los Parlamentos autonómicos, el Congreso y el Senado. En este trabajo se trata de analizar las decisiones adoptadas por los órganos de gobierno para hacer frente a la situación generada por la crisis sanitaria —en la que era esencial la presencia de la institución-, para la que no contaban con previsión reglamentaria ni muchas veces con herramientas tecnológicas suficientes. Frente a algunas soluciones imaginativas, en las que principios como la inmediatez o la presencialidad han sido puestos en cuestión, defendemos que la ductilidad del Derecho parlamentario tiene límites si queremos mantenernos en el Estado de Derecho.

Key words: Parliament, Parliamentary Law, emergency state, Covid-19, pandemic, health crisis, Parliament' work, Territorial Parliaments.

Palabras Clave: Parlamento, Derecho Parlamentario, estado de alarma, Covid-19, pandemia, crisis sanitaria, funcionamiento del Parlamento, Parlamentos autonómicos.

FECHA DE RECEPCIÓN: 11.05.2020

FECHA DE ACEPTACIÓN: 09.09.2020 